\title{
Finite-volume ray tracing using Computational Fluid Dynamics in linear focus CSP applications
}

\author{
K.J. Craiga, ${ }^{a}$, M.A. Moghimi ${ }^{\mathrm{b}}$, A.E. Rungasamyb, J. Marsberg ${ }^{\mathrm{b}}$ \\ and J.P. Meyer ${ }^{\mathrm{a}}$ \\ aProfessor, $P h D$, ' Graduate student, \\ Department of Mechanical and Aeronautical Engineering, University of Pretoria, Pretoria 0002 South Africa \\ *Corresponding author: ken.craig@up.ac.za +27-12-420-3515
}

\begin{abstract}
The modelling of solar irradiation in concentrated solar power (CSP) applications is traditionally done with ray-tracing methods, e.g. the Monte Carlo method. For the evaluation of CSP receivers, the results from ray-tracing codes are typically used to provide boundary conditions to Computational Fluid Dynamics (CFD) codes for the solution of conjugate heat transfer in the receivers. There are both advantages and disadvantages to using separate software for the irradiation and heat transfer modelling. For traditional ray-tracing methods, advantages are the cost-effectiveness of the Monte Carlo method in modelling reflections from specular surfaces; the ability to statistically assign a sun shape to the rays; the statistical treatment of reflectivity and optical errors (e.g. surface slope errors), to name a few. When considering a complex mirror field and a complex receiver with secondary reflective surfaces, especially with selective coatings to enhance absorption and limit re-radiation losses, standard ray tracers may be limited in specifying emissivity and absorptivity, which are both specular and temperature dependent, and are hence not suitable as radiation analysis tool. This type of scenario can be modelled accurately using CFD, through the finite volume (FV) treatment of the radiative transfer equation (RTE) and a banded spectrum approach at an increased computational cost. This paper evaluates the use of CFD in the form of the commercial CFD code ANSYS Fluent v15 and v16 to model the reflection, transmission and absorption of solar irradiation from diffuse and specular surfaces found in linear CSP applications. 2-D CFD solutions were considered, i.e. line concentration. To illustrate and validate the method, two sources were used. The first source was test cases from literature with published solutions and the second a combined modelling approach where solutions were obtained using both FV and ray tracing (with SolTrace). For all the test cases, good agreement was found when suitable modelling settings were used to limit both ray-effect and false scattering errors.
\end{abstract}

Keywords: Computational Fluid Dynamics; Radiative Transport Equation; Discrete Ordinates Method; ray tracing; ray effect; false scattering 


\section{Introduction}

The use of simulation tools like Computational Fluid Dynamics (CFD) in the analyses of energy systems is widespread in the continuous drive to improve the efficiency of energy production by understanding and reducing losses in energy generation. For solar energy generation, especially Concentrated Solar Power (CSP), various research foci can be seen in the literature. For instance, Gadi [1] was one of the pioneering researchers using CFD commercial codes in thermal simulation of a solar water heater. In solar air heater applications, Yadav and Bhagoria [2] performed a review of CFD as used for the analysis of solar air heaters. Allouche et al. [3] simulated fluid flow in the steam ejector of a solar refrigeration system while enhanced heat transfer of parabolic trough absorber pipes are considered by Muños et al. [4]. The analysis of CSP heat storage systems using CFD has been a recent development, with Fornarelli et al. [5], Pointner et al. [6] and Xu et al. [7] being significant examples. In terms of using this modelling approach for solar power plants, Fasel et al. [8] applied CFD for the thermal and fluid flow modeling of a solar chimney power plant. For CSP plants this approach has been used successfully to investigate thermal losses and to analyze the thermal efficiency of different receivers for Linear Fresnel, Parabolic Through and Solar Tower types (Facão and Oliviera [9], Lobón et al. [10] and Garbrecht et al. [11]). Lobón et al. [10], together with Hachicha et al. [12] are examples where CFD is being used for the advanced modeling of complex physics not possible with simpler analysis codes.

Another complex physics example is the topic of this paper, where the application of CFD is extended to not only provide an insight into conjugate heat transfer processes in solar thermal receivers but also to include optical modeling. This has been performed by e.g. Martinek and Weimer [13] in the optical simulation of a solar biomass reactor, but their results could not exactly capture the circumferential heat flux trend around the tube absorbers. Instead they rather focused on Monte Carlo ray tracing techniques which is the predominant approach used for optical simulation. In another example, Hachicha [14] used CFD to capture the optics of a parabolic trough but then linked this to a simplified thermal model of the absorber. Several papers in the literature link a Monte Carlo ray tracinggenerated heat flux profile to a CFD model of the conjugate heat transfer [e.g., 15, 16, 17].

This paper however proves that CFD can be used to provide accurate optical modeling results and therefore opens up the possibilities of a comprehensive computational approach to study the combined optical and thermal performance of different solar power plants.

In doing so, this paper seeks to introduce the finite volume (FV) method into the optical modelling of line focusing CSP, first for test cases from literature and then for two linear Fresnel reflectors (LFRs). CFD provides the user with a more integrated environment for subsequent studies where the optics are combined with conjugate heat transfer and optimization techniques that also allows for spectrum-selective optical properties to be considered in the receiver/absorber design.

In order to model radiation accurately in the CFD environment, [18] suggests the use of the $S_{N}$ or discrete ordinates (DO) method for solving the radiative transfer equation (RTE). This method is the predominant approach because it is easy to implement and the RTE can be solved simultaneously with energy, mass and momentum conservation equations in the CSP application. This provides a unique ability for the DO method to be applied to complex geometries for different participating media such as non-grey, anisotropically scattering, non-isothermal, absorbing and emitting media. However, the DO method has two major 
shortcomings due to the volumetric nature of the solver, namely the introduction of ray effects and false scattering, which affects the accuracy of the results [19-20].

The "ray effect" introduces numerical errors by approximating the continuous angular nature of radiation beam propagation as discrete angular increments. This numerical error may "displace" heat flux peaks within the solution. "False scattering" is a diffusive numerical error linked to the spatial discretisation of the domain that leads to smoothing of the radiation profiles. Several strategies as suggested by [21] to reduce these errors are applied in this paper to a variety of test cases. The commercial CFD code ANSYS Fluent (v15 and v16) is used without any special user coding.

The paper first covers the background of the RTE and its solution using the DO method. Thereafter, brief mention is made of the Monte Carlo ray-tracing method that is used as validation in the subsequent results. The test cases used to compare the FV solution with Monte Carlo ray-tracing results are a test case of oblique collimated radiation [22], radiation in a CSP biomass cavity [23], the LS-2 parabolic collector [24] and then two LFR models using a mono-tube receiver with secondary reflector based on [25]. The first model has a mirror layout based on the FRESDEMO plant [25], while the second is an etendueconserving compact linear Fresnel collector (CLFR) [26], which places flat mirrors along an etendue conservation curve and targets multiple angled mono-tube receivers. For the latter two cases, the Monte Carlo ray-tracing package, SolTrace [27] is used to generate the results used for comparison. Conclusions from the work close the paper.

\section{Method for solving radiation in CFD software}

\subsection{Conservation equations}

When considering the modelling of solar radiation using an FV CFD code, only the energy equation (equation 1) needs to be considered (considering two dimensions only), with the last term requiring special attention:

$$
u \frac{\partial\left(\rho c_{p} T\right)}{\partial x}+v \frac{\partial\left(\rho c_{p} T\right)}{\partial y}=\frac{\partial}{\partial x}\left(k \frac{\partial T}{\partial x}\right)+\frac{\partial}{\partial y}\left(k \frac{\partial T}{\partial y}\right)+\dot{q}_{\text {radiation }}^{\prime \prime \prime}
$$

where $T$ is the temperature, $k$ the thermal conductivity, $\rho$ the density, $u$ and $v$ the velocity components linked with the Cartesian directions $x$ and $y$, and $\dot{q}_{\text {radiation }}^{\prime \prime \prime}$ a radiative term, which describes the rate per unit volume of the net loss of radiative energy from a control volume from a physical viewpoint [28]. This term is equal to the emittance of energy from that volume minus the absorbed incident radiation to it. Therefore, the radiative transfer equation (RTE) should be considered in conjunction with the energy conservation equation in order to determine the radiative term, $\dot{q}_{\text {radiation }}^{\prime \prime \prime}$. In this study, air is considered to be a radiatively transparent medium. When selective coatings or a glass window in front of a receiver aperture is used, at least two non-grey bands have to be considered to model both the specular versus diffuse reflection from opaque surfaces due to surface roughness, as well as to model the wavelength-dependent opaqueness of glass [29]. The non-grey radiation behaviour is then implemented by dividing the radiation spectrum into two wavelength bands with radiation properties remaining fixed in these bands. The bounds of these bands 
are then defined based on typical glass absorption band definitions, e.g. $0-4.25 \mu \mathrm{m}$ and beyond $4.25 \mu \mathrm{m}$ [30]. The RTE is defined as [28]:

$$
\nabla .\left(I_{\lambda}(\vec{r} . \vec{s}) \vec{s}\right)+\beta I_{\lambda}(\vec{r} . \vec{s})=\kappa_{\lambda} n^{2} I_{b \lambda}+\frac{\sigma_{s}}{4 \pi} \int_{0}^{4 \pi} I_{\lambda}\left(\vec{r} \cdot \vec{s}^{\prime}\right) \phi\left(\vec{s} \cdot \vec{s}^{\prime}\right) d \Omega^{\prime} .
$$

In equation 2, the scattering coefficient $\sigma_{s}$, the scattering phase function $\phi$ and the refractive index $n$ are assumed to be independent of wavelength. The terms on the righthand side describe emission and scattering, while the second term on the left-hand side accounts for the absorption of radiation intensity. $I_{\lambda}$ is the radiation intensity, $\kappa_{\lambda}$ is the absorption coefficient, $\beta$ the combination of the absorption and scattering coefficients, and $\Omega$ ' the solid angle. $I_{b \lambda}$ (the blackbody emission in the wavelength band per unit solid angle) is defined as:

$$
I_{b \lambda}=\left[F\left(0 \rightarrow n \lambda_{2} T\right)-F\left(0 \rightarrow n \lambda_{1} T\right)\right] n^{2} \frac{\sigma T^{4}}{\pi}
$$

where $T$ is the local temperature, $\sigma$ the Stefan-Boltzmann constant and $F\left(0 \rightarrow n \lambda_{2} T\right)$ is the fraction of radiant energy emitted by the blackbody in the wavelength interval from 0 to $\lambda$ as defined by the Planck distribution function or blackbody radiation function [31]. Under the grey assumption, the integral in equation 2 becomes a summation such that the net loss of radiative energy from a control volume is computed as follows:

$$
\dot{q}_{\text {radiation }}^{\prime \prime \prime}=-\sum_{k=1}^{n_{\text {last }}} \kappa_{\lambda_{k}}\left(4 \pi \pi_{b \lambda_{k}}(\vec{r} . \vec{s})-G_{\lambda_{k}}\right) \Delta \lambda_{k}
$$

where $n_{\text {last }}$ is the last defined band number and $G_{\lambda_{k}}$ is the incident radiation function (the total intensity impinging on a point from all sides), which is computed for each band as follows [28]:

$$
G_{\lambda}=\int_{4 \pi} I_{\lambda}\left(\vec{s}^{\prime}\right) d \Omega^{\prime}
$$

\subsection{Radiative surface properties}

In radiation analysis, four radiative properties (absorptance $\alpha$, emittance $\varepsilon$, reflectance $\rho$ and transmittance $\tau$ ) must be specified for each surface. For local thermal equilibrium of a surface and the adjacent fluid layer, Kirchhoff's law reduces the properties to three, because in each wavelength band

$$
\alpha_{\lambda}=\varepsilon_{\lambda}
$$

Based on the definition of the radiative properties of a surface, in each wavelength band, 
the following relation holds:

$$
\alpha_{\lambda}+\rho_{\lambda}+\tau_{\lambda}=1
$$
wall:

The transmission into an opaque surface is zero by definition, implying that for an opaque

$$
\rho_{\lambda}=1-\varepsilon_{\lambda} .
$$

The reflected energy can be reflected either specularly (in one direction as for a mirror) or diffusely, due to surface roughness. Both types of reflections have the same amount of total reflected energy implying that the amount of diffuse reflection in any direction is less that the total specular amount. In radiation terminology, a rough surface is a surface of which the height of its roughness is much larger than the incident radiation wavelength. So, if the root mean square (RMS) surface roughness is less than incident radiation wavelength, then the surface acts as specular [32], else it acts as diffuse.

Opaque surfaces inside the receiver geometries are considered to reflect diffusely in the short-wavelength band and spectrally in the long-wavelength band. The glass surface (when present) is considered to be highly polished with a negligible surface roughness (RMS $\sim 0$ ) [33], and hence spectral reflection is prescribed on the glass walls for the whole wavelength domain.

Diffuse (non-specular) versus specular reflection is defined in ANSYS Fluent using a diffuse fraction parameter $f_{d}$ for each band. If $f_{d}$ equals one, it means purely diffuse reflection whereas a zero value implies pure specular reflection for that band.

For non-grey opaque walls, by combining Kirchoff's law and the radiative surface energy balance, the incident radiative heat flux over a surface would be

$$
q_{i n, \lambda}^{\prime \prime}=\Delta \lambda \int_{\vec{s} \cdot \vec{n}>0} I_{i n, \lambda} \vec{s} \cdot \vec{n} d \Omega
$$

where $\vec{n}$ is the surface normal unit vector. The net radiative flux leaving the surface in a band is

$$
q_{o u t, \lambda}^{\prime \prime}=f_{d}\left(1-\varepsilon_{w \lambda}\right) q_{i n, \lambda}^{\prime \prime}+\left(1-f_{d}\right)\left(1-\varepsilon_{w \lambda}\right) q_{i n, \lambda}^{\prime \prime}+\varepsilon_{w \lambda}\left[F\left(0 \rightarrow n \lambda_{2} T\right)-F\left(0 \rightarrow n \lambda_{1} T\right)\right] n^{2} \sigma T_{w}{ }^{4}
$$

where $\varepsilon_{w \lambda}$ is the wall emissivity in the band and $n$ the refractive index as first defined in equation 2 . At the wall, the boundary intensity for all outgoing directions in a specific band $\Delta \lambda$ is given by

$$
I_{0 \lambda}=\frac{q_{\text {out }, \lambda}^{\prime \prime}}{\pi \Delta \lambda}
$$

It should be mentioned that for a non-grey diffuse semi-transparent wall, the heat flux on the two sides of a medium is calculated using equations 9 and 10 for each medium, while the incident intensity $I_{\text {in }}$ is calculated from a complicated mathematical equation (omitted for brevity [28]), which is related to the refractive indices for the media. 


\subsection{Discrete ordinates method and $\mathrm{S}_{\mathrm{N}}$ approximation}

The numerical procedure that was considered for solving RTE inside the domain is the discrete ordinates (DO) method or $\mathrm{S}_{\mathrm{N}}$ approximation as introduced by [28] and implemented in [34] as $\mathrm{S}_{2}$. The reason for choosing this method for solving the RTE was the capability of the DO method to model semi-transparent media. "Ordinate" refers to a direction in hemispherical space. For each ordinate passing in one direction, there will be another ordinate in the opposite direction. For that reason, there will be an even number of directions in $\mathrm{S}_{\mathrm{N}}$ approximation.

In a 2-D simulation in ANSYS Fluent using the $S_{2}$, each quadrant of angular space is discretised into $N_{\theta} \times N_{\phi}$ of solid angles (control angles) with a fixed vector direction $\vec{s}$ in the global Cartesian system (see Figure 1). For 1-D, $2 \times N_{\theta} \times N_{\phi}$ directions of the RTE equations are solved, for 2-D, $4 \times N_{\theta} \times N_{\phi}$ directions, while for $3-\mathrm{D}, 8 \times N_{\theta} \times N_{\phi}$ directions are computed, implying that the computational overhead and memory requirements increase linearly with each angular discretisation division and that for each spatial dimension that is added, the overhead doubles. These control angles are then divided into subdivisions (pixellations). The DO method solves the RTE for a finite number of control angles while the incoming or outgoing radiation to each control angle face is computed by the energy contained in each pixel. In this study, the RTE is uncoupled from the energy equation, implying that at each cell, the RTE and energy equation are solved sequentially with the two equations linked through a correction term in the latter (equation 1). The DO thermal radiation model in ANSYS Fluent [34] can be used to model a solar irradiation source field by defining semi-transparent walls at the boundary of the computational domain.

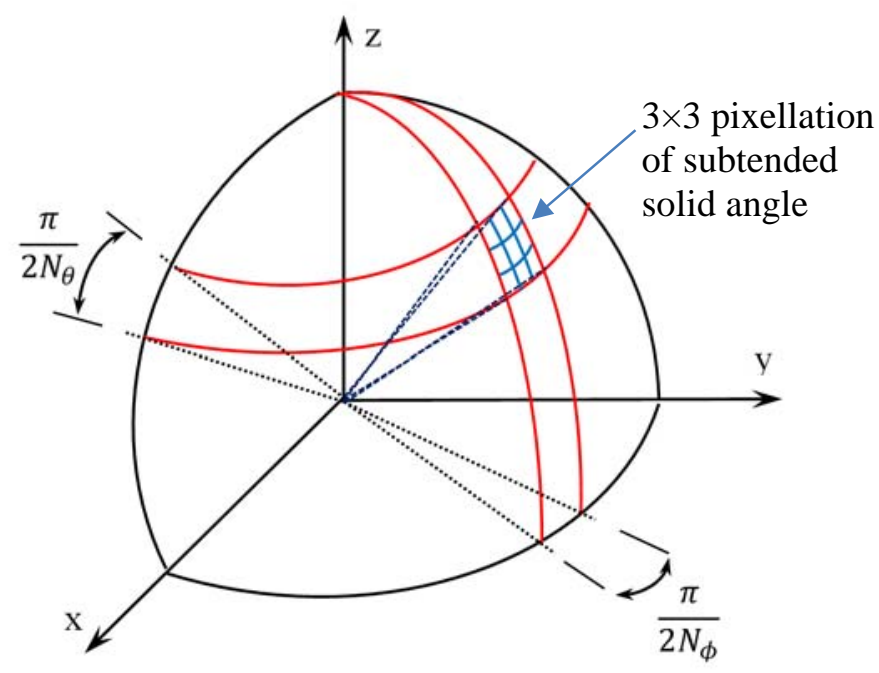

Figure1: Definition of angular discretization and pixellation used in DO method for $S_{2}$

The DO method has two major shortcomings due to the volumetric nature of the solver, namely the introduction of ray effects and false scattering, which affects the accuracy of the 
results [19. 20. 35]. The "ray effect" (also known as "ray concentration” [13]) introduces numerical errors by approximating the continuous angular nature of radiation beam propagation as discrete angular increments [19]. This numerical error may "displace” heat flux peaks in the solution and its effects can be reduced by choosing a higher number of ordinate directions (high-order $S_{N}$ method), effectively increasing the number of subdivisions (control angles), i.e. minimising the solid angle extents [14. 36]. "False scattering” (also known as "numerical smearing/scattering” or "false diffusion” [14. 22. 37]) is a diffusive numerical error linked to the spatial discretisation of the domain. It leads to smoothing of the radiation profiles and can be countered through refining the mesh used in the model, using more accurate spatial discretisation schemes [14] or aligning the mesh with the direction of radiation beam propagation [20. 38].

In order to counteract these shortcomings, practical strategies were suggested by [21]:

1. choosing a higher-order $\mathrm{S}_{\mathrm{N}}$ method $\left(\mathrm{S}_{4}, \mathrm{~S}_{8}, \mathrm{~S}_{16}, \ldots\right)$,

2. increasing the control angle count,

3. increasing the spatial mesh count, and;

4. using a higher-order spatial discretisation scheme for the DO direction equations.

Some of these options are available within open-source CFD or user-defined CFD codes, however, commercial CFD packages restrict the user's ability to change the order of the $\mathrm{S}_{\mathrm{N}}$ method. In ANSYS Fluent, e.g. only $\mathrm{S}_{2}$ is provided and first- and second-order discretisation of the DO equations are available.

\section{Monte Carlo ray tracing (MCRT)}

For comparison, this paper uses SolTrace, a public domain Monte Carlo ray tracer (MCRT) [27]. There are many ray tracers available either publicly (SolTrace, Tonatiuh [39], Tracer [40]) or commercially (e.g., HFLCAL, SPRAY, SOLFAST [41]) based on MCRT technology as discussed by [42] and [43]. They can be used in isolation to evaluate the optical performance of receivers thereby providing the solar load distribution on a candidate absorber geometry. MCRT methodology consists of following stochastic paths of a large number of rays as they interact with reflecting, absorbing or transmitting surfaces. Each ray carries the same amount of energy and has a specific direction determined from an appropriate probability density function based on the defined sun shape. The interaction of each ray with surfaces depends on the transmissive, reflective and absorptive behaviour of the surface, which is described by a set of statistical relationships [44]. Band-selective reflection, absorption or emission and complex geometries require special treatment and for these applications, CFD FV is preferred by the authors.

\section{Test cases}

\subsection{Test case 1: Oblique radiation into cavity}

As a first illustration of the interaction between FV mesh density and the angular discretisation of the DO in reducing both the ray effect and false scattering, a test case from literature [22], with an available Monte Carlo ray-tracing result, is used.

The domain (illustrated in Figure 2) has oblique collimated radiation entering into a black square enclosure filled with a pure isotropically scattering and homogeneous medium 
$\left(\sigma_{s}=1 \mathrm{~m}^{-1}, \kappa=0\right.$ in equation (2)). The oblique angle is defined by $\theta=-90^{\circ}, \phi=-60^{\circ}$ and enters through a transparent section of the top wall $(0 \leq x \leq 0.2)$. The other walls of the enclosure are perfectly opaque and cold ( $0 \mathrm{~K}$ Temperature). The reason for choosing this case study was to see how well ANSYS Fluent deals with specular radiation with discontinuities (the expected step change in heat flux on the bottom wall).

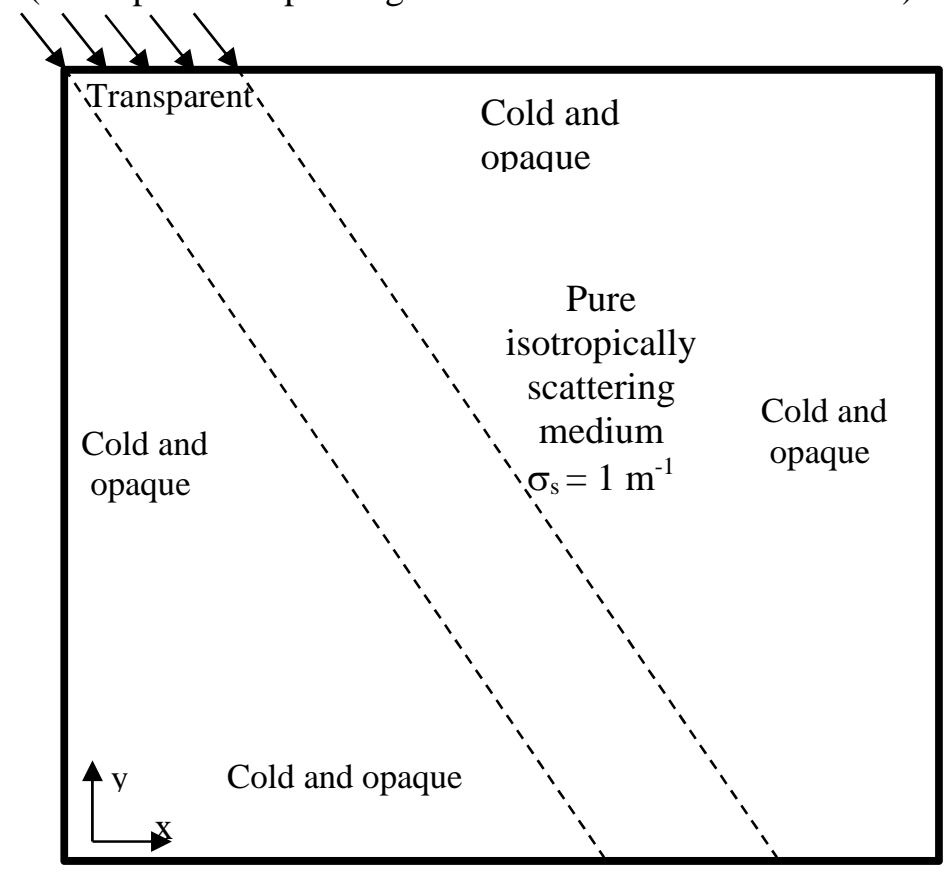

Figure 2: Configuration of oblique collimated radiation case study [22]

A structured Cartesian mesh is used (as in [14]) in order to have an unaligned mesh with the incident radiation direction. This means that false scattering in the computational domain is expected.

The results are reported in Figure 3 and are compared with the Monte Carlo solution [22]. The following notation is used:

$N_{x} \times N_{y}-N_{\theta} \times N_{\phi-}$ Pixel $_{\theta} \times$ Pixel $_{\phi}$ Order of spatial discretisation on DiscreteOrdinates $_{2}$ where the first two terms $\left(N_{x}, N_{y}\right)$ are the number of cells along $x$ - and $y$-directions respectively, the next four specify the angular discretisation and pixellation in the two angular coordinates and the last term specifies either first- or second-order discretisation as available in ANSYS Fluent.

For this domain, the effect of varying the mesh density, then increasing the angular discretisation divisions, changing the discretisation order and lastly combining the optimal combination of these settings is illustrated in Figure 3 when using ANSYS Fluent. Note that the value of $N_{\theta}$ needs only to be set to 3 in the second dimension if the 2-D coordinate system is appropriately chosen. In Figure 3a, the ray effect due to an insufficient number of angular discretisations is obvious, as the focus of the incoming oblique ray misses the intended target as illustrated by the comparative accurate Monte Carlo ray-tracing solution. The ray-effect error decreases with increasing $N_{\theta} \times N_{\phi}$ and the peak of each curve shifts towards the expected solution where, due to heat flux step change (between $x=0.577$ and 
$x=0.777$ ), a peak in the curve is evident. Settings finer than $N_{\phi}=40$ do not result in a change in the peak location, implying that the ray-effect error is minimised at this setting. It is, however, clear that some false scattering remains.

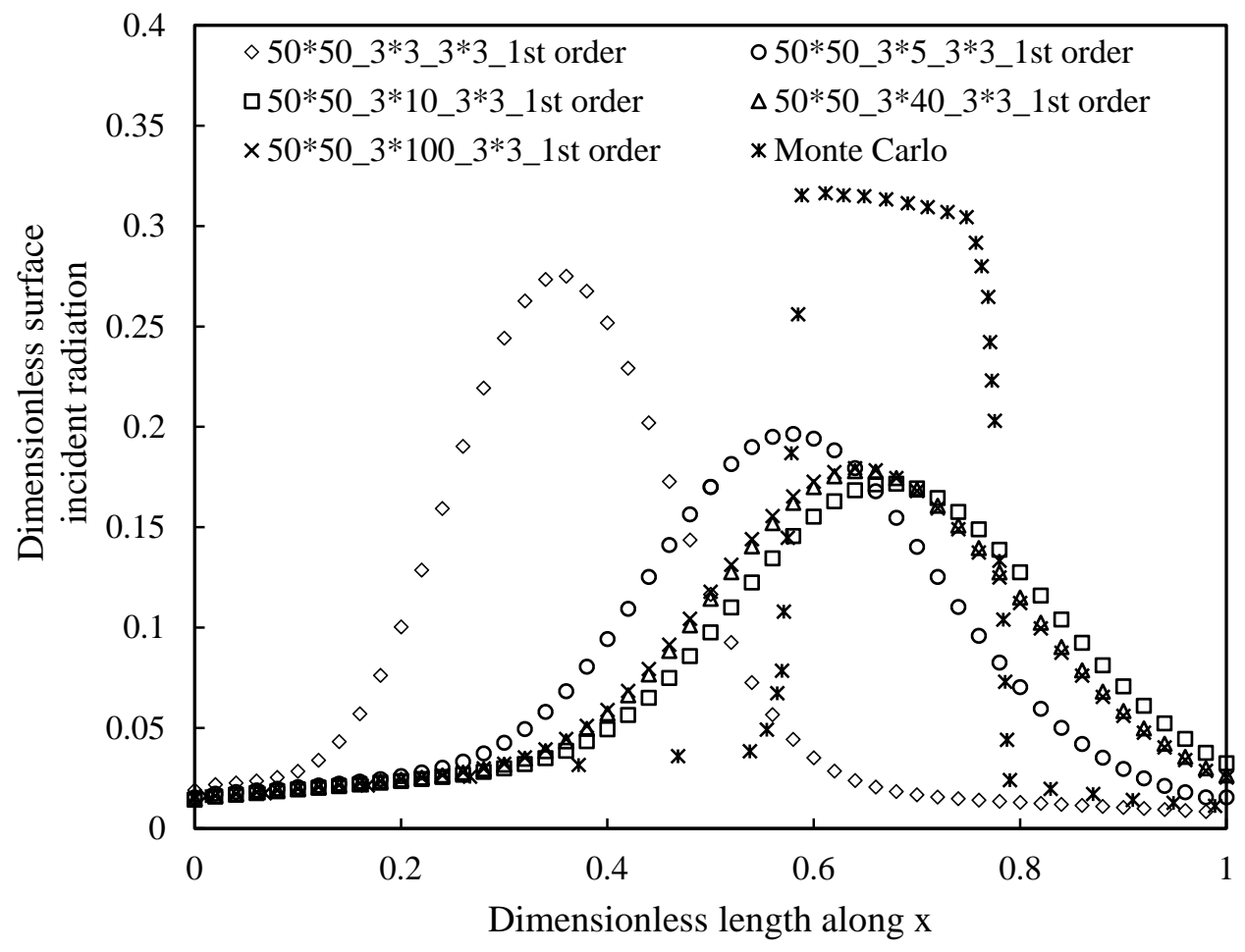

(a) 


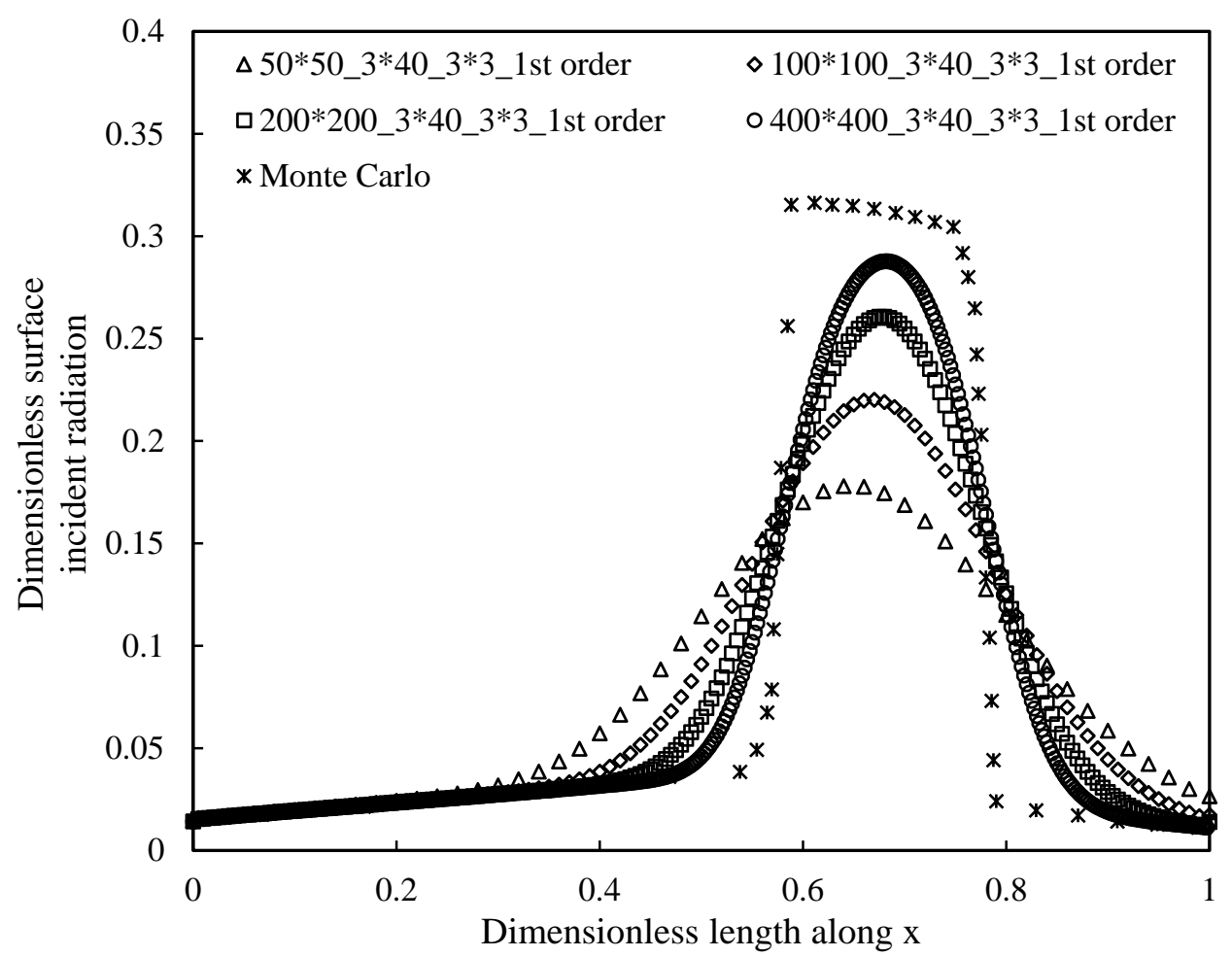

(b)

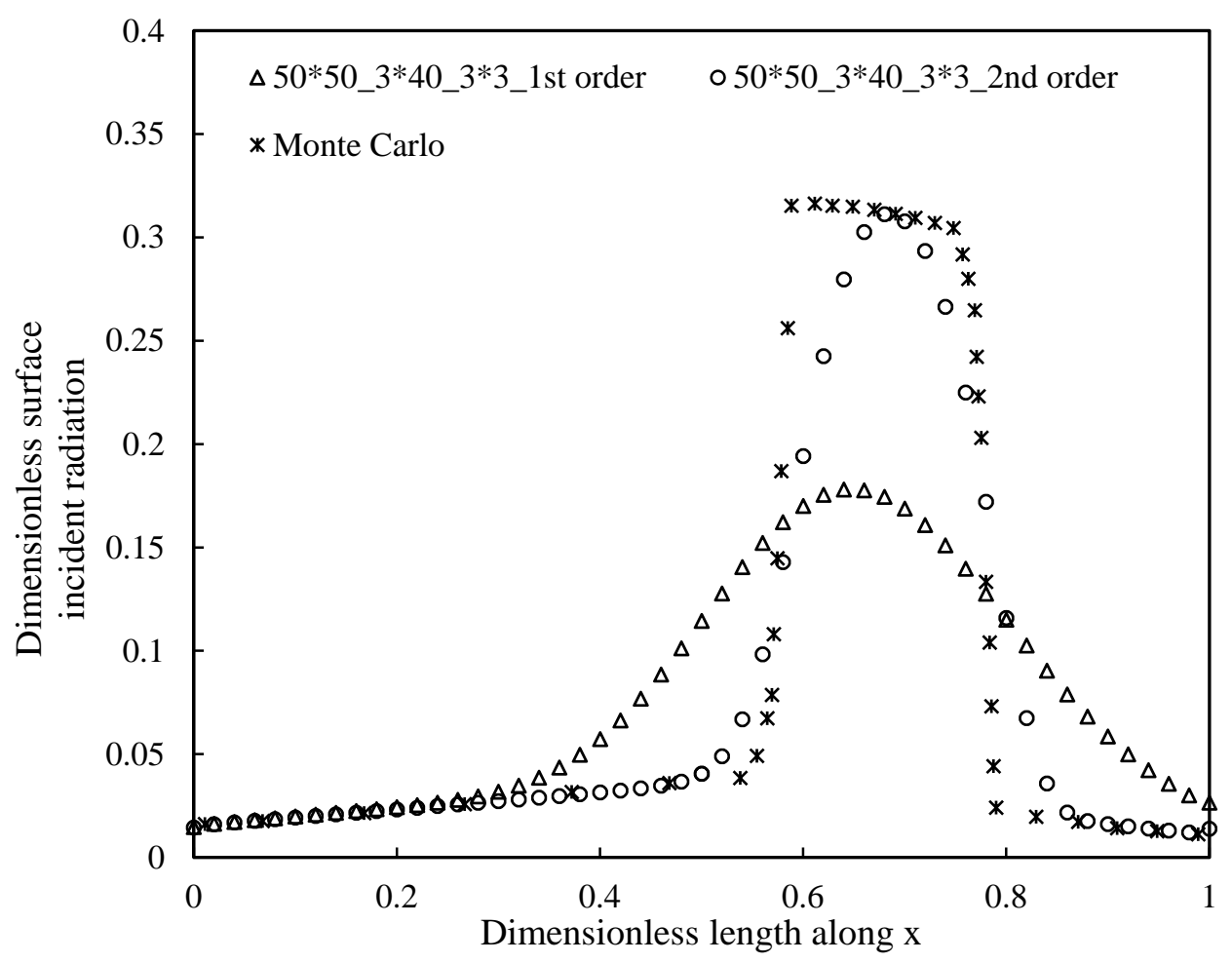

(c) 


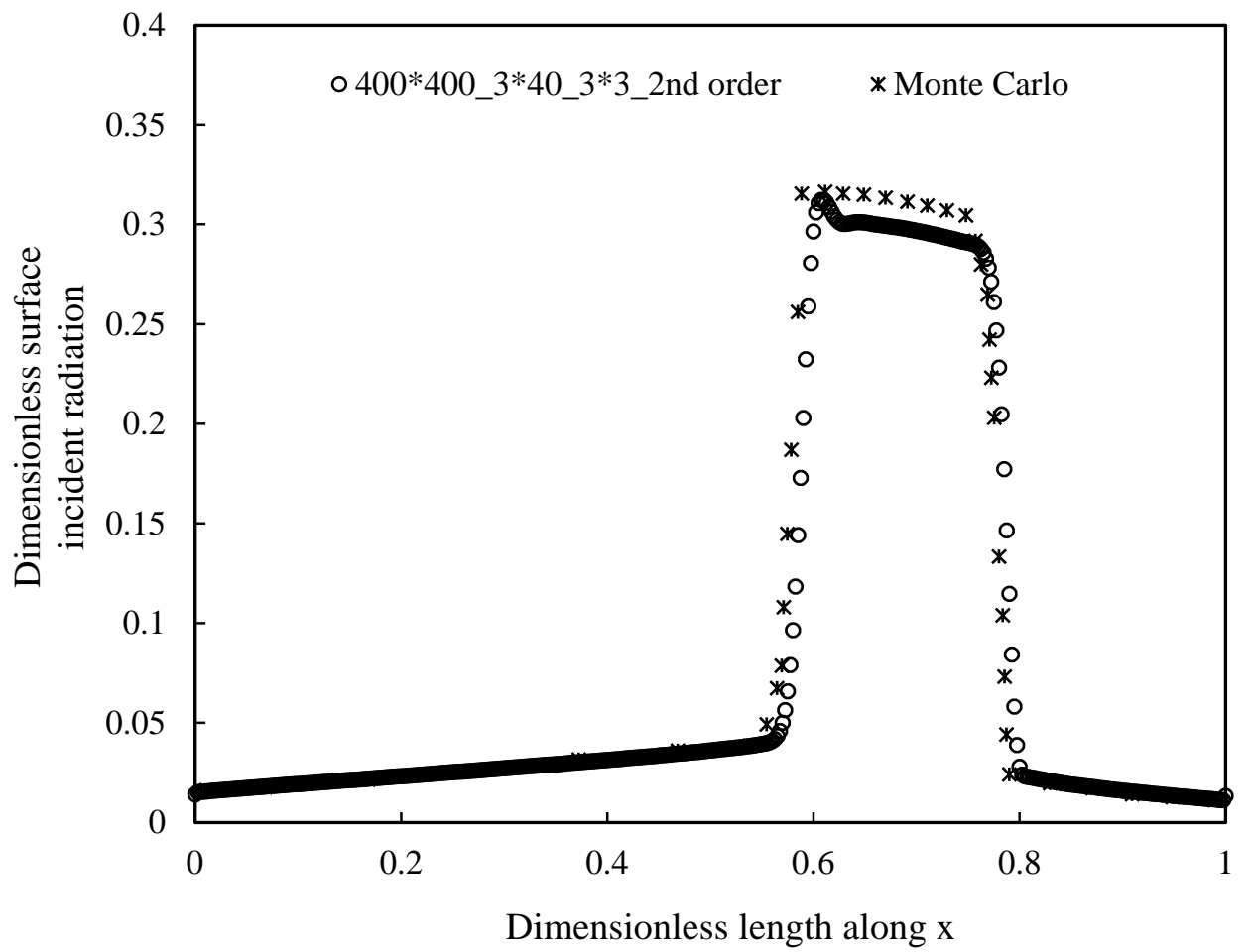

(d)

Figure 3: Variation of a) angular discretisation, b) mesh density, c) discretisation order, d) optimal combination of settings; for oblique collimated radiation test case, as compared with Monte Carlo solution [22].

Symbols enumerated according to $N_{x} \times N_{y-} N_{\theta} \times N_{\phi-}$ Pixel ${ }_{\theta} \times$ Pixel $\phi$ _- Order of spatial discretisation DO

In order to reduce the false scattering error, the effects of refining the spatial grid and using a more accurate spatial discretisation scheme for the sufficient ray-effect reduction case $\left(N_{\phi}=40\right)$ are investigated separately in Figures $3 \mathrm{~b}$ and $3 \mathrm{c}$ respectively. The reduction in the smearing of the wave front is noted as the mesh is refined (Figure 3b) but the sharp discontinuity in absorbed radiation is not captured, even for the finest mesh (eight-fold increase).

Second-order discretisation improves the smearing in a marked fashion. Figure 3c shows that switching to second-order spatial discretisation sharpens the peak even for the coarsest mesh $(50 \times 50)$ for the case that reduced the ray-effect error $\left(3 \times 40 \_3 \times 3\right.$ for angular discretisation), but it does not perfectly predict the Monte Carlo solution that exhibits a flat peak. Finally, by combining all of the above methods, the false scattering and ray effect can be significantly reduced, with the discontinuity captured to some extent (Figure 3d).

The effect of refining the mesh, the angular discretisation and order of discretisation can be understood when viewing the incident radiation contours for all the cases discussed in Figure 3. Figure 4 shows the progression in terms of incident radiation contours corresponding to that displayed in Figure 3. The minimisation of the ray effect with increasing angular discretisations is illustrated as the beam shifts towards the correct location in Figure 4a; the beam intensity increases with a finer computational mesh in Figure 4b, whilst Figure 4c shows that second-order discretisation leads to a sharper discontinuity. 
Using a mesh that is aligned with the expected incident radiation pattern (after [14]) does improve the accuracy for lower DO settings by virtue of the fact that false scattering due to a misaligned mesh is largely removed. Figure 5 shows this mesh. The incident radiation contours in Figure 6 confirm the reduction in beam strength as the incident radiation is isotropically scattered and shows how the ray effect is removed with an increase in the angular discretisation intervals. The surface incident radiation on the lower surface as plotted in Figure 7 confirms that for more than 10 control angles, the location of the step change is accurately captured as the ray-effect error is reduced. The aligned mesh gives a peak value that is higher than that reported by [22] for the Monte Carlo method. This value remained fixed as the mesh was refined further or the number of ordinate angles increased.

\subsection{Test case 2: Tubes in biomass cavity}

The second test case (reported by [13]) as taken from [23]) considers a more complex cavity geometry but still considers collimated radiation entering it. Figure 8 [23] shows the cross-section of the biomass cavity, which is modelled in ANSYS Fluent. [13] reports results for a reflective as well as an absorbing cavity. Since the reflective cavity poses a more challenging environment for the FV method, and because the physical cavity tested by [23] had a reflective cavity wall, only the reflective cavity will be considered here. The boundary conditions can be summarised as follows:

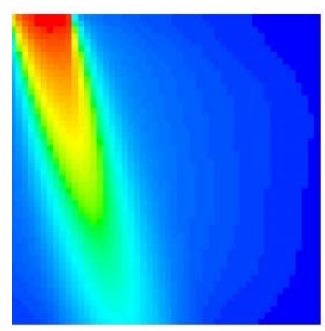

$50 \times 50 \_3 \times 3 \_3 \times 3$

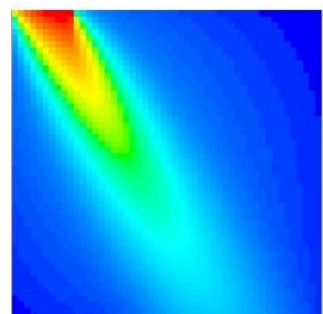

50×50_3×40_3×3

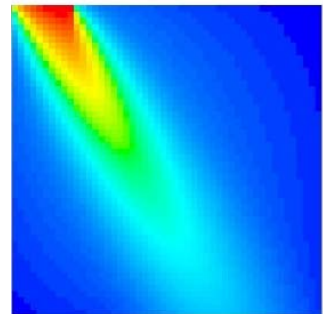

50×50_3×40_3×3

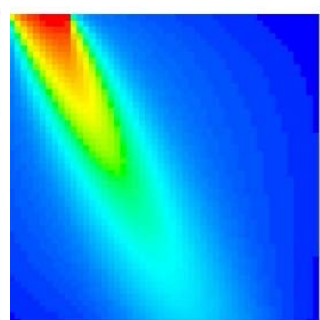

$50 \times 50 \_3 \times 5 \_3 \times 3$

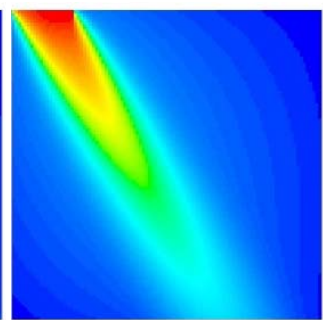

$100 \times 100 \_3 \times 40 \_3 \times 3$

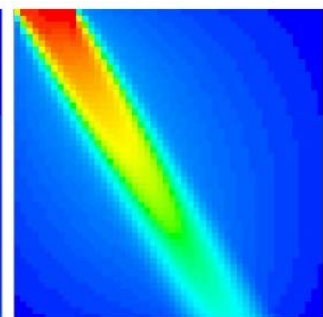

50×50_3×40_3×3 $2^{\text {nd }}$ order

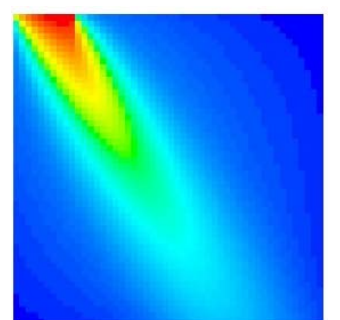

$50 \times 50 \quad 3 \times 10 \quad 3 \times 3$

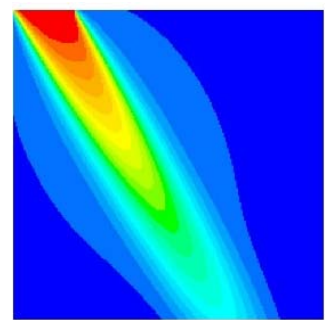

200×200_3×40_3×3

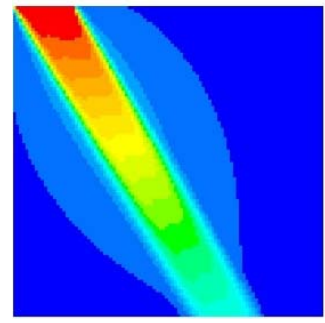

$100 \times 100$ _3 $\times 40 \_3 \times 3$ $2^{\text {nd }}$ order

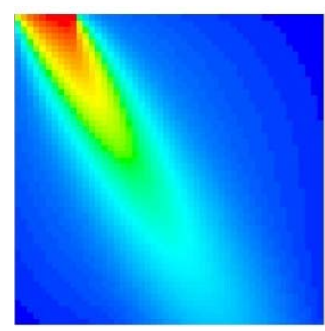

$50 \times 50 \quad 3 \times 40 \quad 3 \times 3$

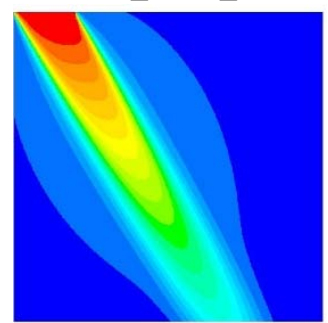

400×400_3×40_3×3

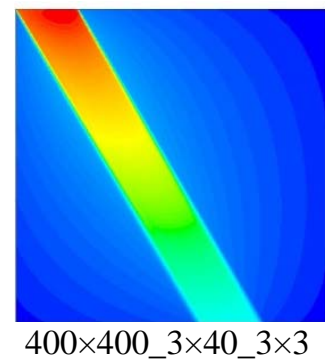

$2^{\text {nd }}$ order (a)

(b)

(c) 
Figure 4: Incident radiation contours for variation of a) angular discretisation ( $\left(1^{\text {st }}\right.$ order), b) mesh density ( $1^{\text {st }}$ order $)$, c) discretisation order $\left(1^{\text {st }}\right.$ and $\left.2^{\text {nd }}\right)$ and optimal combination of settings; for oblique collimated radiation test case

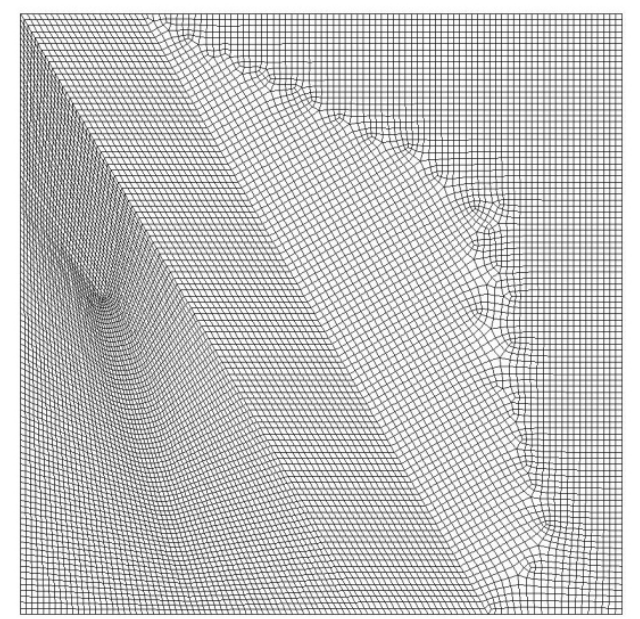

Figure 5: Aligned mesh for oblique collimated radiation test case (edges have 100 elements

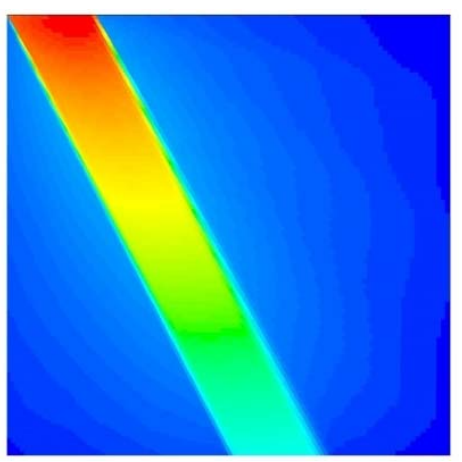

$3 \times 5 \_3 \times 3 \_2^{\text {nd }}$ order

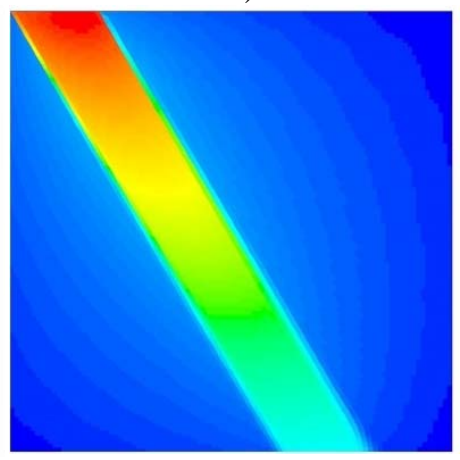

3×10_3×3_2 $2^{\text {nd }}$ order

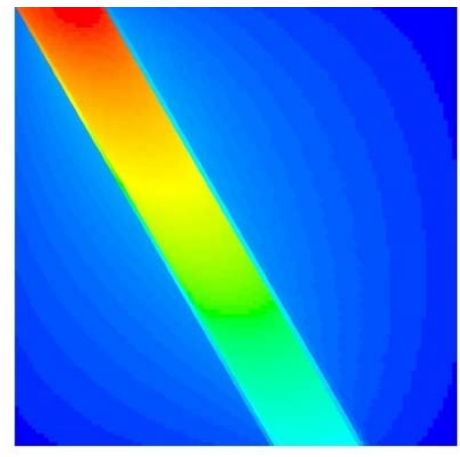

3×40_3×3_2 $2^{\text {nd }}$ order

Figure 6: Incident radiation contours for oblique collimated radiation test case as a function of DO angular discretisation on aligned mesh (edges have 100 elements each) 


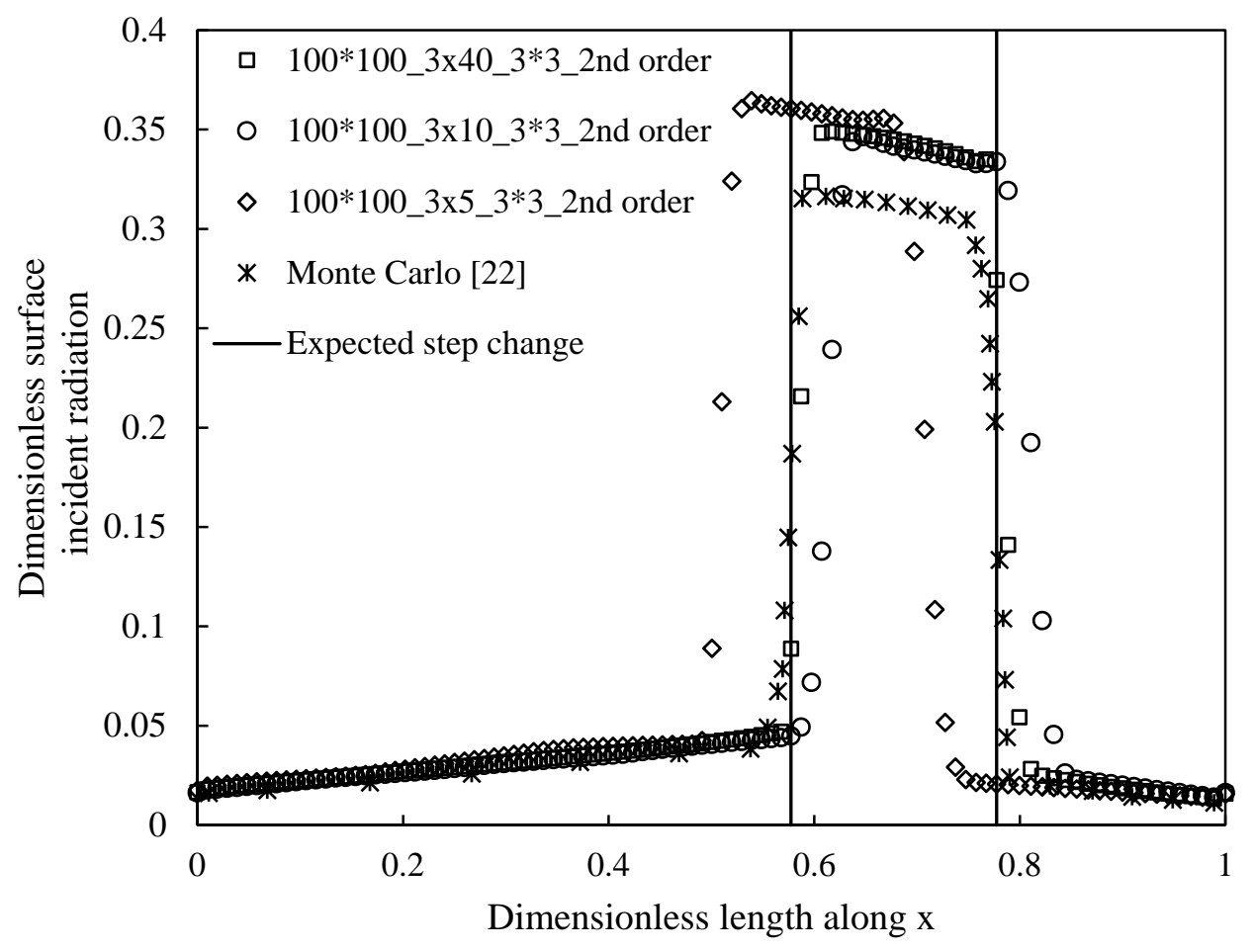

Figure 7: Variation of angular discretisation on aligned mesh for oblique collimated radiation test case, as compared with Monte Carlo solution [22]

- Collimated radiative heat flux $\left(1 \mathrm{~W} / \mathrm{m}^{2}\right.$ to obtain a normalised value automatically) enters normally through the semi-transparent wall at the aperture. Collimated radiation was obtained by specifying a beam width angle of 5e-6 for $\theta$ and $\phi$. Using the ANSYS Fluent-recommended values of $1 \mathrm{e}-6$ led to asymmetric results at lower DO settings. A full geometry model was considered and not a half geometry model as solved by [13]. The use of a full model was motivated by the interest in seeing whether a slightly asymmetric mesh would cause asymmetry in the results.

- $\quad$ All surfaces within the cavity are kept at $0 \mathrm{~K}$ to make re-radiation effects negligible.

- Pipe walls have an absorptivity of 0.96 [13] and reflect diffusely (diffuse fraction of one in ANSYS Fluent).

- Cavity walls are assumed to be mostly reflecting (absorptivity $=0.9$ ) and specular (zero diffusion fraction). 


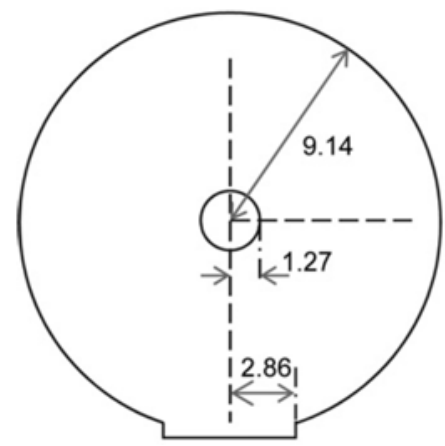

(a)

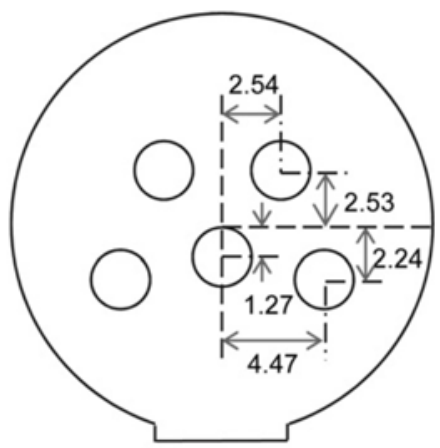

(b)

Figure 8: Biomass receiver configuration for (a) one pipe, (b) five pipes [13] - dimensions in inches

A mesh refinement and DO discretisation sensitivity study was conducted, of which sample results are presented below. It was found that the DO settings used by [13] of $5 \times 5$ and $15 \times 15$ were insufficient to accurately capture the surface incident radiation profiles on the pipe and cavity wall. In addition, as reported elsewhere in this paper, the number of DO discretisations $\left(N_{\theta}\right)$ in the one planar 2-D dimension needs only to be set to 3. It was found that levels of $3 \times 50$, i.e., $N_{\phi}=50$ and above were sufficient for accurate answers depending on the mesh resolution. Second-order discretisation of the DO equation is used in this and all subsequent test cases.

Comparative results using SolTrace are displayed in Figure 9 to illustrate how the rays interact with the pipe(s). These plots allow qualitative comparison with the CFD results presented below. For the single pipe (Figure 9a), a reflective pattern forms, which has two peaks around the circumference of the cavity wall (from the Monte Carlo results below). For the five-pipe case (Figure 9b), note that the incoming collimated rays should miss the front left and front right pipes if there is no ray effect or false scattering present.

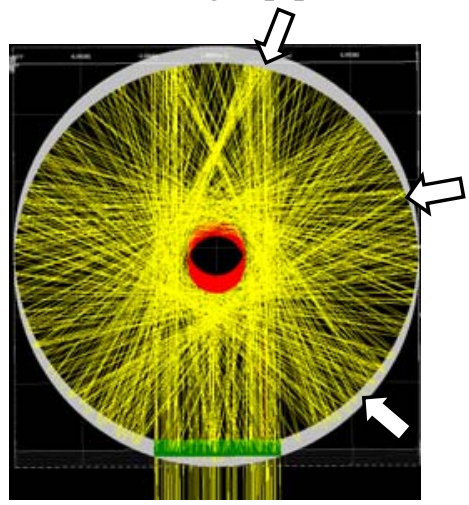

(a)

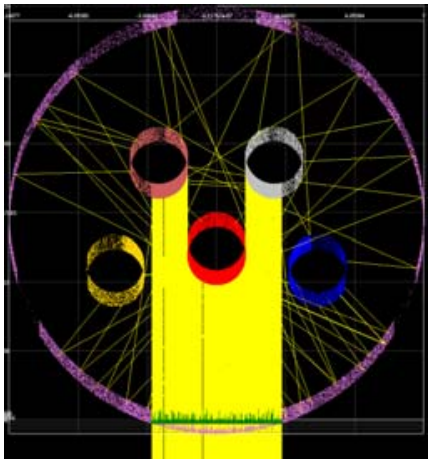

(b)

Figure 9: Illustration of SolTrace ray tracing for biomass cavity: (a) single pipe with reflective cavity wall, (b) five-pipe cavity with reflective cavity wall (1 000000 desired ray intersections). Concentrated incident radiation areas indicated by arrows.

Figure 10 compares the normalised radiation heat flux distributions around the pipe and the cavity wall as calculated using ANSYS Fluent with those obtained by [13]. Referring to Figure 10a, the current results on the front of the pipe closely match the Monte Carlo results, while on the rear of the pipe, there is some flux absorbed because of ray-effect and false 
scattering errors of the reflected radiation. Increasing the mesh resolution improves the comparison on the front and the back of the pipe. An increase in the DO discretisation from $3 \times 50$ to $3 \times 100$ does not lead to a significant improvement in the comparison. For the cavity wall (Figure 10b), the results are more interesting because of the complex reflection pattern. A DO setting of $3 \times 50$ is sufficient with a finer mesh bringing a slight improvement in the first reflection (around $170^{\circ}$ ) peak prediction as well as in both side reflection peaks.

Figure 11 shows incident radiation contours for DO settings of $3 \times 5$ and $3 \times 100$ to illustrate the ray-effect and false scattering errors. One cannot distinguish between the two errors because both false scattering and ray-effect errors lead to the beam entering the aperture propagating in the wrong direction when it passes the pipe. Once it hits the cavity wall behind the pipe, its reflection directions are wrong and the whole domain experiences inaccurate reflection and absorption patterns as illustrated in Figure 10. The low DO setting (Figure 11a) clearly leads to an incorrect result when compared with the SolTrace plot in Figure 9a.

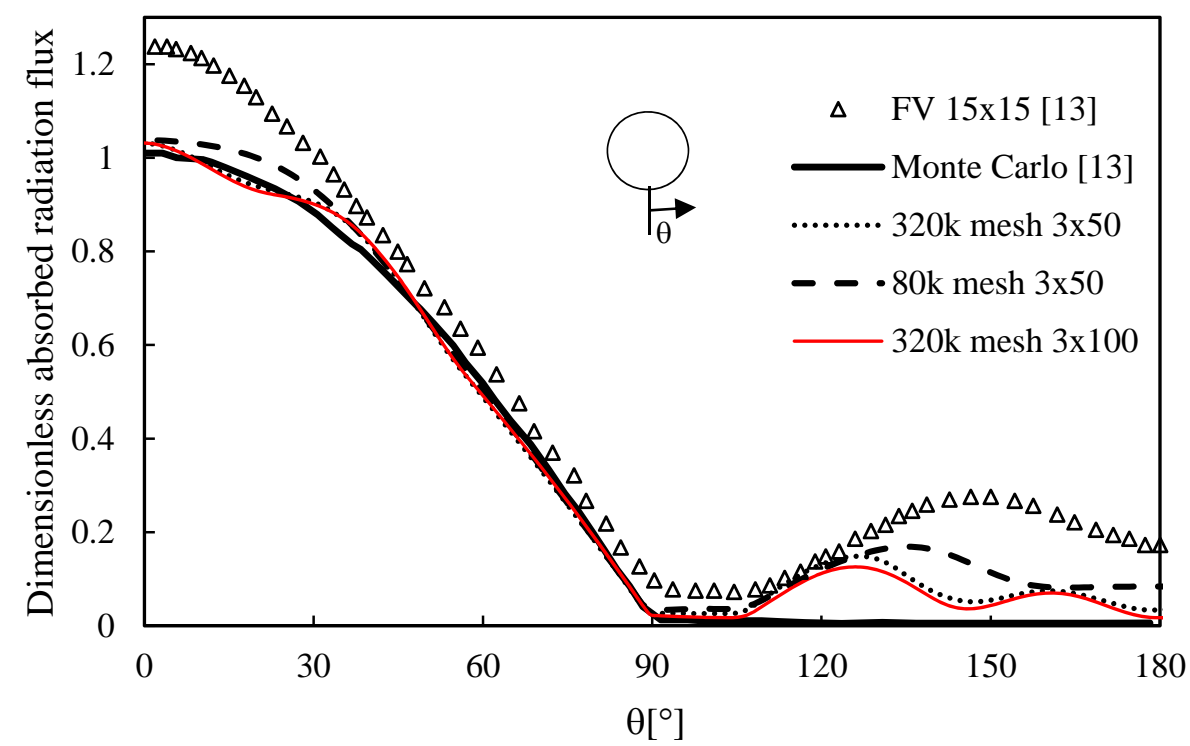

(a) 


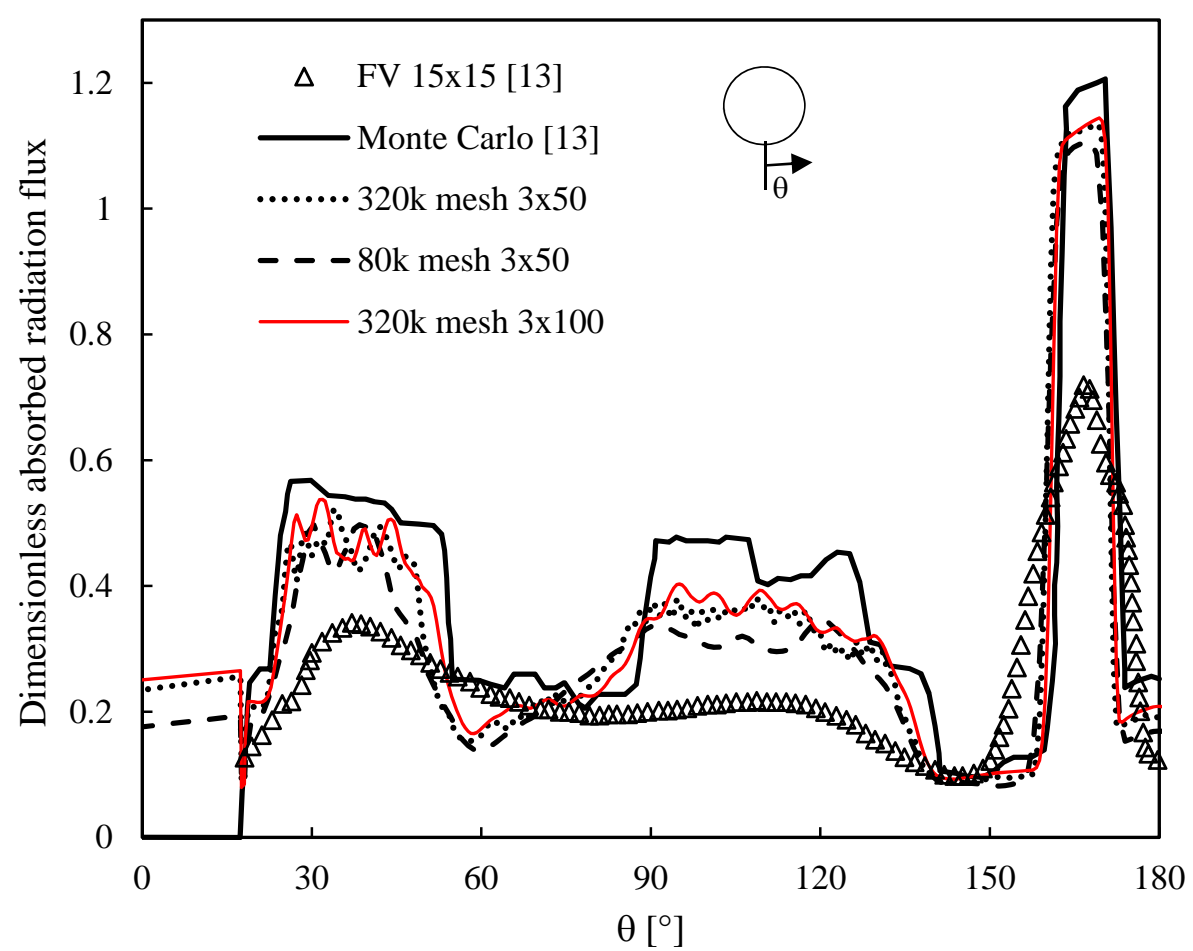

(b)

Figure 10: Normalised heat flux on pipe surface for a single pipe (a) pipe wall (b) cavity wall. Compared with Monte Carlo [13]. Current results on $3 \times 50$ with $80 \mathrm{k}$ and $320 \mathrm{k}$ mesh counts on full geometry. [13] $(\Delta): 15 \times 15$ (83 700 mesh on half geometry)

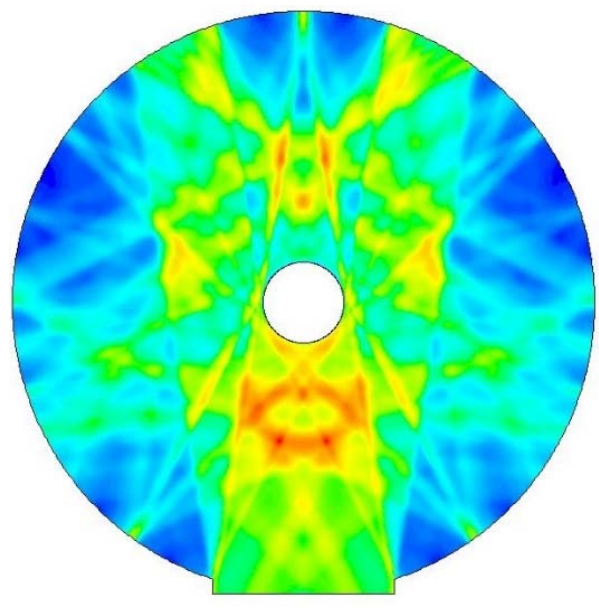

(a)

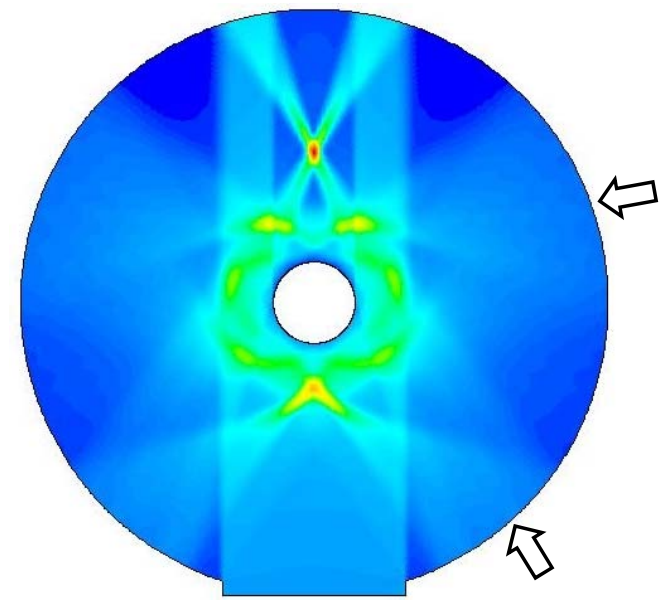

(b)

Figure 11: Incident radiation contours for one-pipe reflective cavity (320k mesh) illustrating rayeffect error with DO setting (a) $3 \times 5$, (b) $3 \times 100$. High incident radiation areas indicated by arrows.

Figure 12 compares the normalised radiation heat flux distributions around the right front 
and back pipes as calculated using ANSYS Fluent with those obtained by [13]. Referring to Figure 12a, the impacting radiation on the rear pipe is accurately captured with a DO setting of $3 \times 50$ and above. The right front pipe (Figure 12b) should not receive any direct radiation but only a background level of specular and diffuse radiation because of the absorptivities of 0.9 and 0.04 on the cavity and pipe walls respectively. The higher DO setting of $3 \times 100$ was required to match the current FV solution with the Monte Carlo data of [13].

The incident radiation contours in Figure 13 illustrate how the CFD method's ray effect and false scattering are decreased when the DO discretisation is increased, eventually leading to negligible radiation being absorbed by the front pipes and comparing favourably with the SolTrace plot in Figure 9b.

\subsection{Test case 3: SEGS LS-2 parabolic trough collector}

This test case considers a linear focus CSP application in the form of the LS-2 parabolic trough collector (PTC) used in the SEGS plant as tested at Sandia [24]. The Monte Carlo results of [45] are used for comparison. Case 1 in that study has an incoming DNI of 933.7 $\mathrm{W} / \mathrm{m}^{2}$, assumed to have an incidence angle of $0^{\circ}$. This value is applied at the top surface and given a beam width of $9.3 \mathrm{mrad}$ or $0.53^{\circ}$. A uniform sunshape profile is assumed. The geometric details of the parabolic trough and its absorber tube are depicted in the computational domain in Figure 14 and Table 1. A symmetric half of a 2-D geometry is solved with an initial mesh count of 89613 cells. The mesh is clustered around the absorber to improve the resolution of the incident radiation gradients in this region.

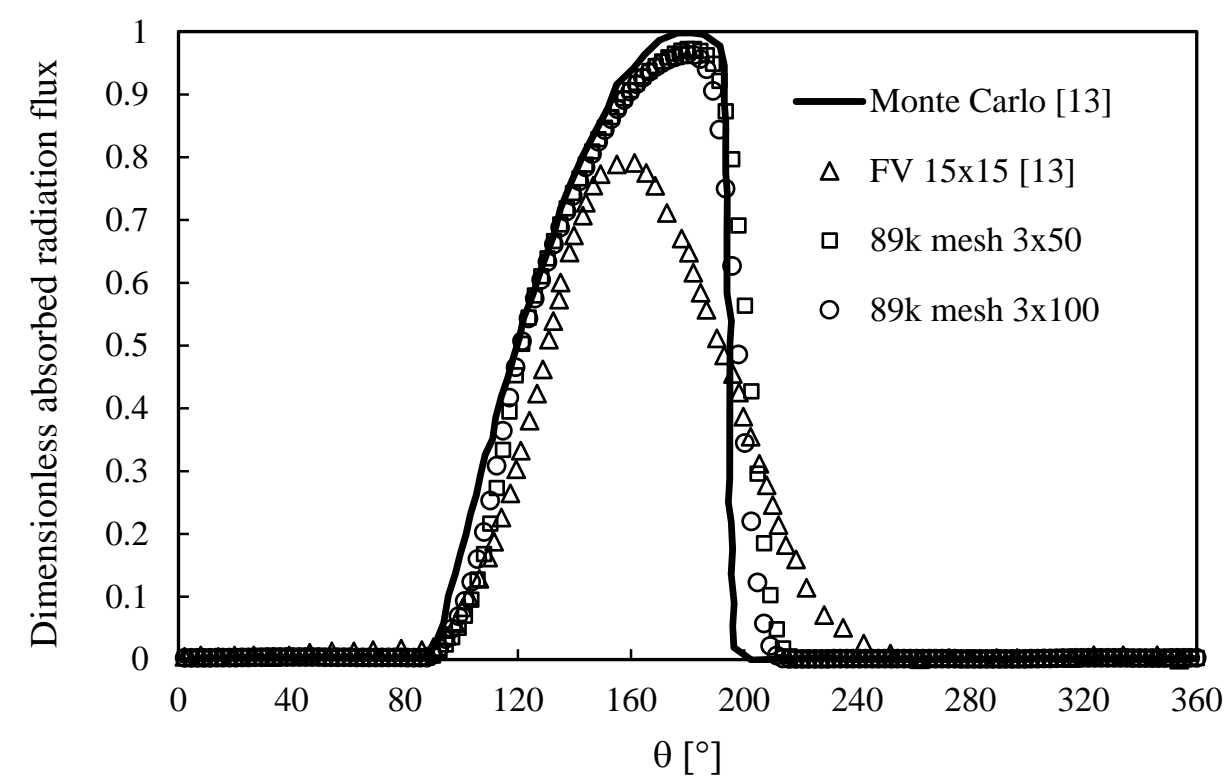

a) 


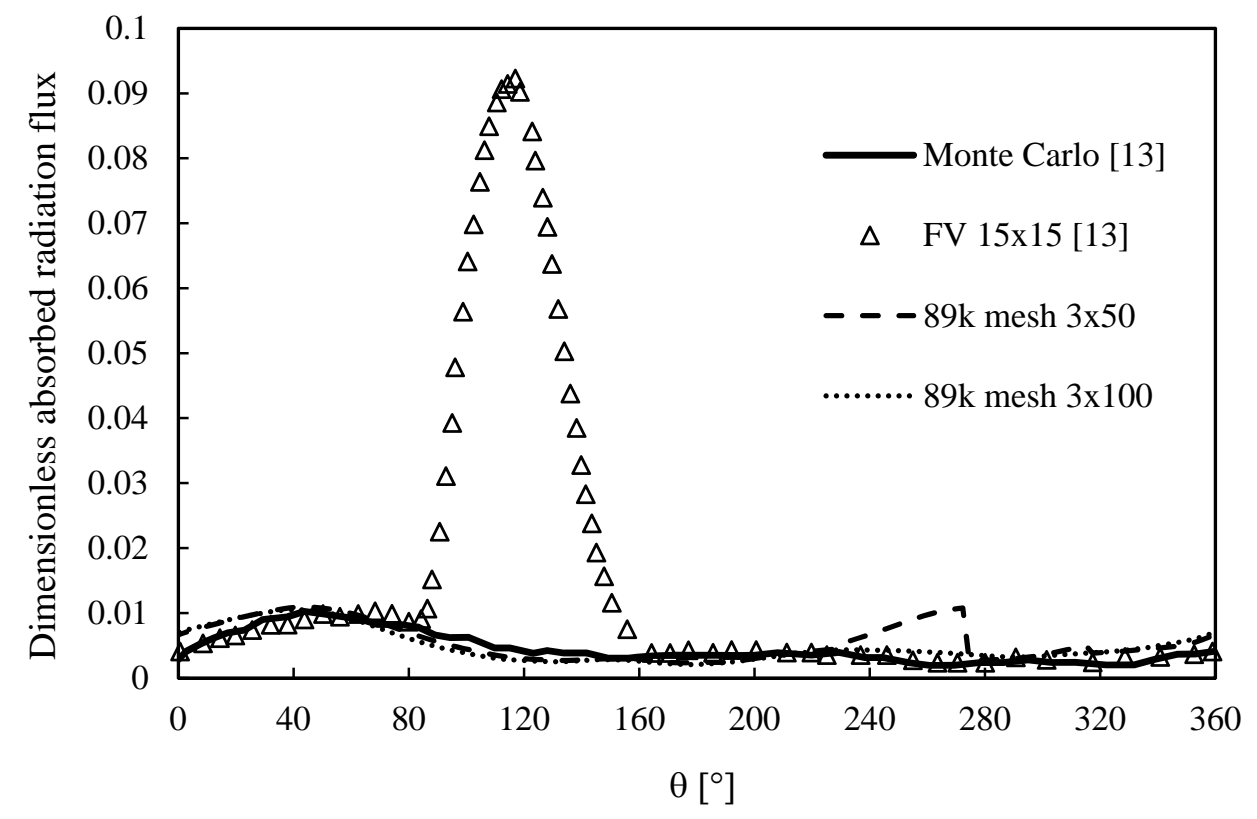

b)

Figure 12: Normalised heat flux on right (a) back, (b) front pipe surface for a five-pipe reflecting cavity compared with Monte Carlo (solid line) [13]. Current results: DO settings $3 \times 50$ and $3 \times 100$, 89k mesh. [13] $(\Delta): 15 \times 15$ (80 789 mesh on symmetric half model)

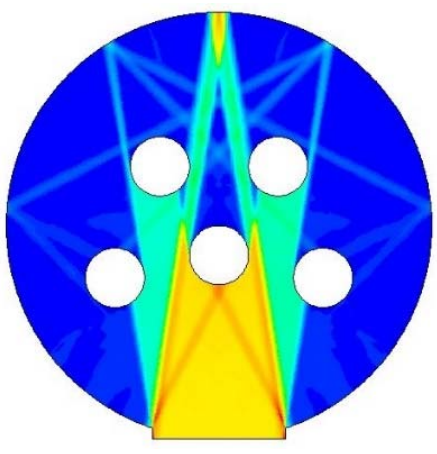

(a)

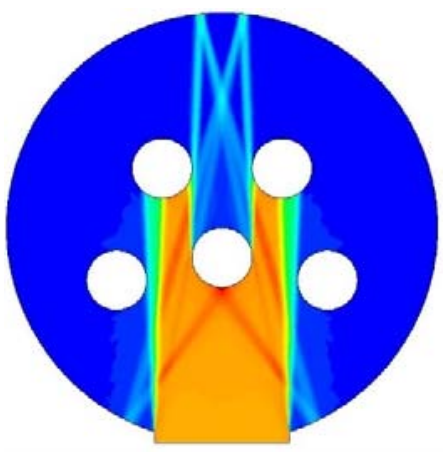

(b)

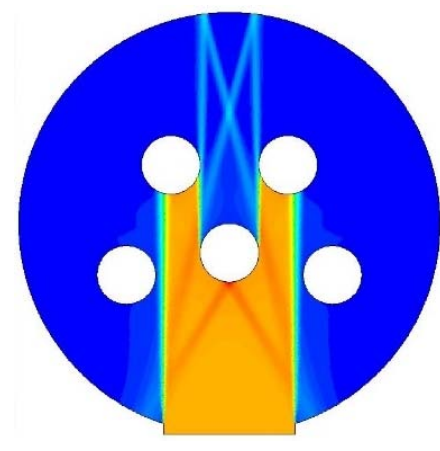

(c)

Figure 13: Incident radiation contours for five-pipe reflective cavity (89k mesh) illustrating rayeffect error with DO setting (a) $3 \times 5$, (b) $3 \times 20$ and (c) $3 \times 50$

Table 1: Properties of SEGS LS-2 parabolic trough collector [24]

\begin{tabular}{|l|l|l|l|l|l|l|l|}
\hline $\begin{array}{l}\text { Collector } \\
\text { aperture } \\
{[\mathrm{m}]}\end{array}$ & 5 & $\begin{array}{l}\text { Focal } \\
\text { distance [m] }\end{array}$ & 1.84 & $\begin{array}{l}\text { Absorber pipe } \\
\text { external } \\
\text { diameter [m] }\end{array}$ & 0.07 & $\begin{array}{l}\text { Glass external } \\
\text { diameter [m] }\end{array}$ & 0.115 \\
\hline $\begin{array}{l}\text { Glass } \\
\text { thickness } \\
{[\mathrm{mm}]}\end{array}$ & 3 & $\begin{array}{l}\text { Receiver } \\
\text { solar } \\
\text { absorptance }\end{array}$ & 0.96 & $\begin{array}{l}\text { Glass } \\
\text { transmittance }\end{array}$ & 0.95 & $\begin{array}{l}\text { Spectral } \\
\text { reflectance of } \\
\text { parabola }\end{array}$ & 0.93 \\
\hline
\end{tabular}




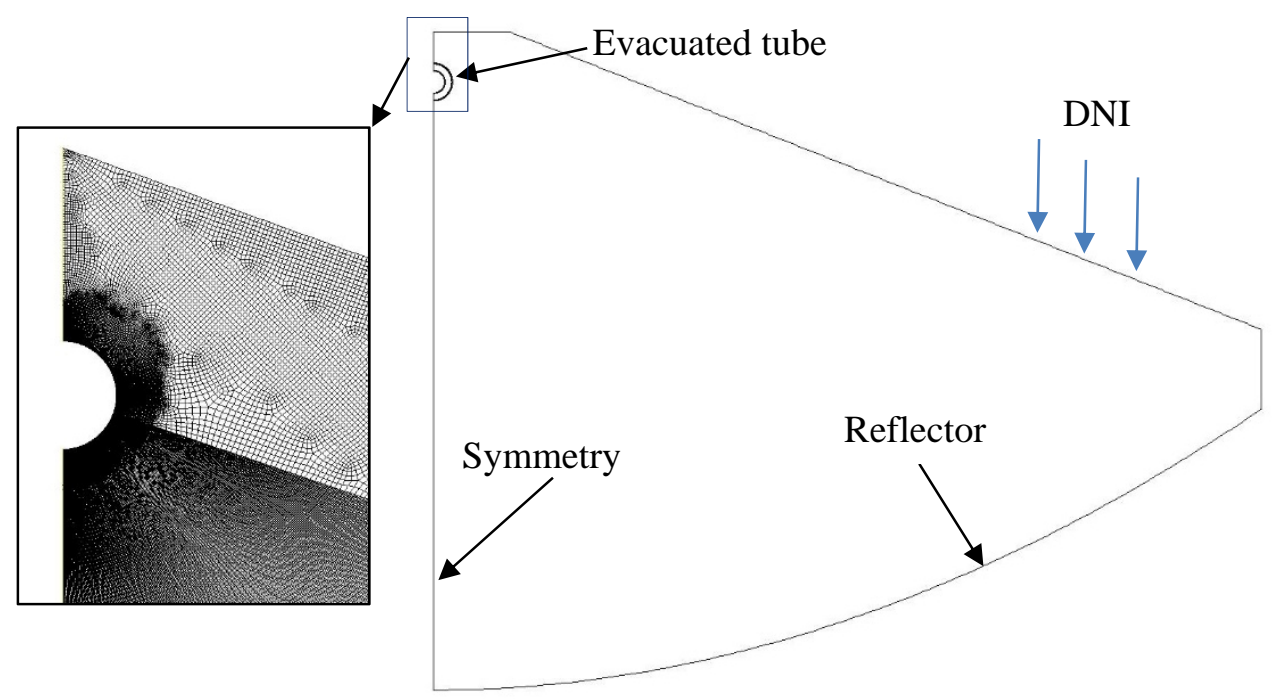

Figure 14: Computational domain of LS-2 PTC with insert showing mesh in absorber tube region (338k mesh case)

The absorber pipe is surrounded by an evacuated tube made of glass with an absorptance of 0.05 (based on Table 1). The absorption coefficient of a semi-transparent participating medium relative to its absorption [28] is defined in equation (12):

$$
\alpha_{\eta}=1-\tau_{\eta}=1-e^{-\kappa_{\eta} s}
$$

where $\alpha_{\eta}$ and $\tau_{\eta}$ are the absorptivity and transmissivity at a specific wavenumber respectively, $s$ the thickness of the medium and $\kappa_{\eta}$ the absorption coefficient [m $\left.{ }^{-1}\right]$. Hence the glass (with 3mm thickness) has an absorption coefficient of $17.10 \mathrm{~m}^{-1}$.

Figure 15 shows the incident radiation contours in the computational domain for a sample case and Figure 16 the circumferential distribution of absorbed solar flux around the pipe as compared with the results obtained by [45] and [14]. Refining the mesh (from 89k to $338 \mathrm{k}$ cells) did not have as large an effect as refining the DO discretisations (from $3 \times 200$ to $3 \times 600$ ) on the heat flux distribution. The peak flux is underpredicted by about $4 \%$ at the highest mesh and DO setting. Further refinement (not shown) did not result in any improvement. The extent of shadow effect calculated by [45] was not captured. This was, however, also not captured by [14] and the current results agree well with those obtained by [14] in the shadow region (around $-90^{\circ}$ in Figure 16). 


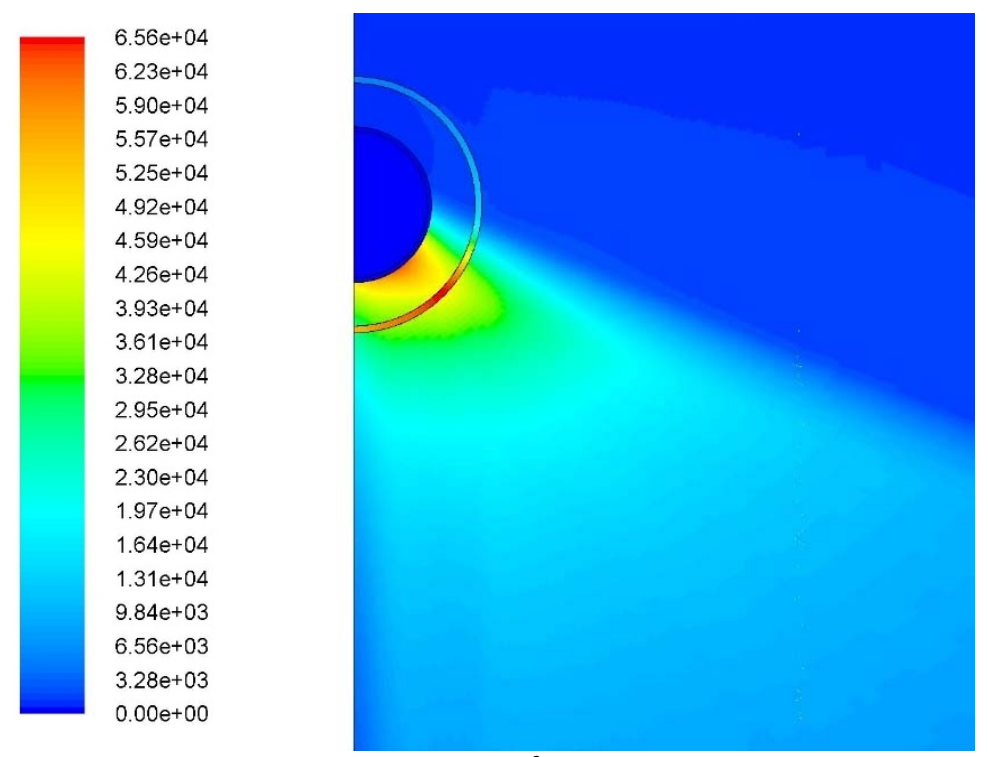

Figure 15: Incident radiation contours $\left[\mathrm{W} / \mathrm{m}^{2}\right]$ for a DO setting of $3 \mathrm{x} 600,89 \mathrm{k}$ mesh

\subsection{Test case 4: Standard linear Fresnel reflector with mono-tube cavity receiver}

A linear Fresnel reflector (LFR) mirror field and trapezoidal cavity receiver were evaluated using FV CFD and SolTrace by [21], with the difference between the two solutions (average absorbed radiation) reported to be $0.22 \%$. The same mirror field (see Table 2 for properties) is used in this test case, but the receiver is replaced by a mono-tube with secondary reflector very similar to the FRESDEMO project $[25,46]$.

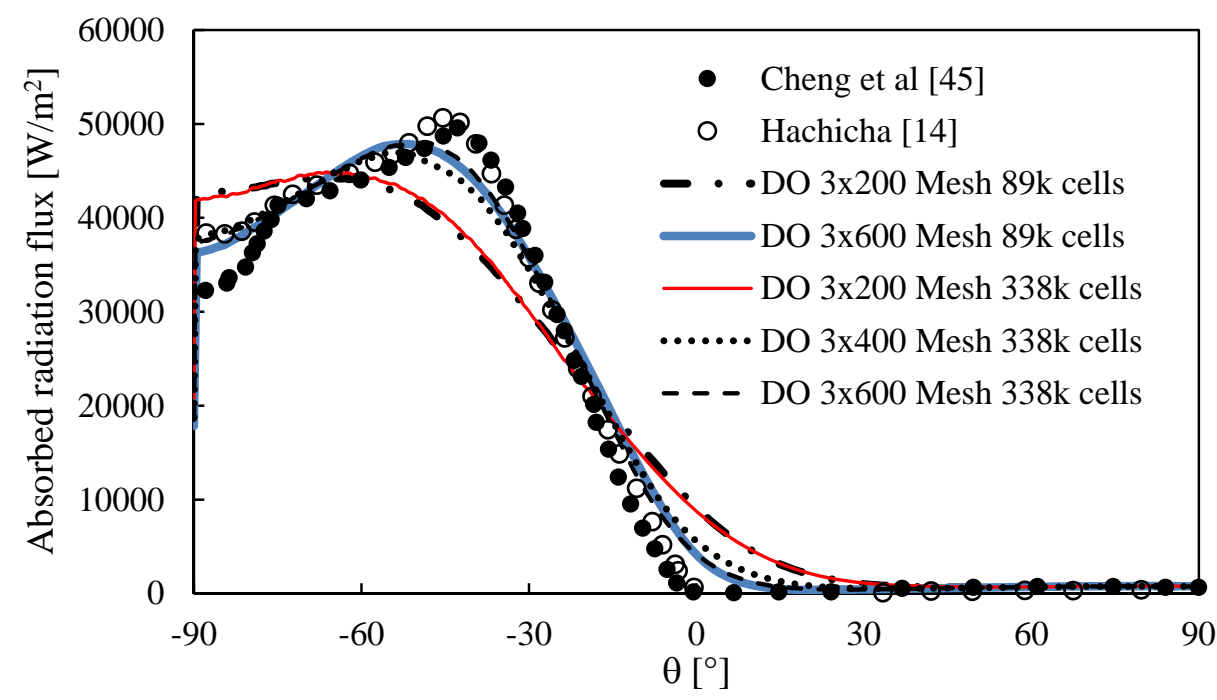

Figure 16: Circumferential distribution of absorbed radiation flux: CFD vs MCRT results of [45] and optical model of [14] 
The curves of the secondary reflector were approximated by creating a curve fit through extracted points from the NOVATECH cavity design [47]. The tube outer diameter was changed to $70 \mathrm{~mm}$. A glass window is situated at the aperture of the cavity to limit thermal re-radiation and the effects of forced and natural convection. For comparison with SolTrace, no absorption is modelled for the glass solid material as in [29], only refraction through the glass. The computational domain, material properties and boundary conditions are detailed in Figure 17 and Tables 3 and 4, respectively. A mesh and DO independence study yielded a 477454 cell mesh and a 3×200 DO discretisation, while the ray count sensitivity study in SolTrace required a minimum of a million rays.

Table 2: Dimensions of LFR mirror field

\begin{tabular}{|l|l|l|l|l|l|l|l|}
\hline $\begin{array}{l}\text { Number of } \\
\text { primary mirrors }\end{array}$ & 25 & $\begin{array}{l}\text { Solar field } \\
\text { width }(W \\
[\mathrm{m}])\end{array}$ & 21 & $\begin{array}{l}\text { Primary mirror } \\
\text { width }(w[\mathrm{~m}])\end{array}$ & 0.6 & $\begin{array}{l}\text { Receiver height } \\
(H[\mathrm{~m}])\end{array}$ & 8 \\
\hline
\end{tabular}

Table 3: Material properties of LFR model materials

\begin{tabular}{|c|c|}
\hline Material & Properties \\
\hline & Thermal conductivity $=0.0242[\mathrm{~W} / \mathrm{m}-\mathrm{K}]$, \\
Solid air & Specific heat $=1006.43[\mathrm{~J} / \mathrm{kg}-\mathrm{K}]$, \\
in and around cavity & Density $=1.225\left[\mathrm{~kg} / \mathrm{m}^{3}\right]$, \\
& Refractive index $=1$, \\
& Absorption coefficient $=0[1 / \mathrm{m}]$, \\
\hline Semi-transparent glass & Thermal conductivity $=1.5[\mathrm{~W} / \mathrm{m}-\mathrm{K}]$, \\
& Specific heat $=786[\mathrm{~J} / \mathrm{kg}-\mathrm{K}]$, \\
& Density $=2650\left[\mathrm{~kg} / \mathrm{m}^{3}\right]$, \\
& Refractive index $=1.5$, \\
& Absorption coefficient $=0[1 / \mathrm{m}]$, \\
\hline
\end{tabular}

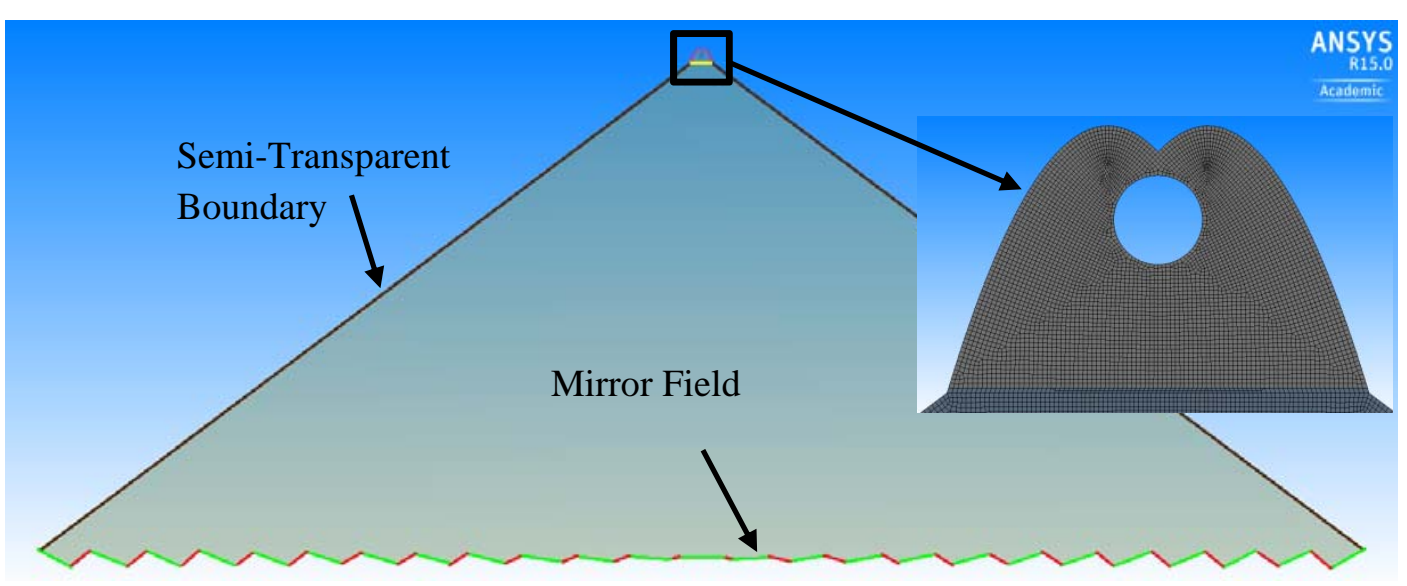

Figure 17: Computational domain of LFR mirror field and receiver with insert showing mesh in cavity receiver region

Figure 18 shows the incident radiation contours and Figure 19 the SolTrace results, with the detailed absorbed and reflected radiation profiles detailed in Figure 20 and integrated amounts in Table 5. The CFD solution yields reasonably accurate results when compared with SolTrace for the mono-tube with a secondary reflector cavity. The deviation is partly 
due to rays not focussing on the tube but on the secondary reflector (see insert in Figure 18) due to ray effect and false scattering errors. This error is quantified in Figure 20b where it can be seen that the reflected radiation flux off the secondary reflector is overestimated in the CFD. Table 5 confirms that this overestimation is around $32 \%$ but this error for the secondary reflector only results in a $0.6 \%$ error in the tube absorbed radiation.

The higher percentage error of the CFD model's integrated absorbed radiation value than that obtained by [21] for the trapezoidal cavity is likely due to the secondary's additional concentrating effect, which creates a higher accuracy requirement of the radiation model due to the directional complexity of the incoming radiation. 
Table 4: Boundary conditions for 2-D FV CFD simulation of optical domain

\begin{tabular}{|c|c|c|c|c|c|}
\hline Surface & BC type & $\begin{array}{l}\text { Thermal } \\
\text { condition }\end{array}$ & $\begin{array}{c}\text { Temperature } \\
\text { [K] }\end{array}$ & Emissivity & Others \\
\hline $\begin{array}{l}\text { Solar field top } \\
\text { side }\end{array}$ & $\begin{array}{c}\text { Semi- } \\
\text { transparent }\end{array}$ & \begin{tabular}{|c|} 
Constant \\
temperature
\end{tabular} & 1 & 1 & $\begin{array}{c}\text { Beam width } \\
\theta=0.53^{\circ} \& \\
\phi=0.53^{\circ}, \\
\text { Direct } \\
\text { Irradiation }=1000 \\
{\left[\mathrm{~W} / \mathrm{m}^{2}\right] \text { downwards }}\end{array}$ \\
\hline $\begin{array}{l}\text { Solar field right } \\
\text { side and gaps } \\
\text { between mirrors }\end{array}$ & $\begin{array}{l}\text { Opaque and } \\
\text { black body }\end{array}$ & $\begin{array}{c}\text { Constant } \\
\text { temperature }\end{array}$ & 1 & 1 & - \\
\hline Mirrors & $\begin{array}{c}\text { Opaque and } \\
\text { pure reflective }\end{array}$ & $\begin{array}{c}\text { Constant } \\
\text { temperature }\end{array}$ & 1 & 0 & - \\
\hline $\begin{array}{l}\text { Solar field left } \\
\text { side }\end{array}$ & Symmetry & - & - & - & - \\
\hline $\begin{array}{l}\text { External } \\
\text { surfaces of } \\
\text { insulation }\end{array}$ & Opaque & $\begin{array}{c}\text { Constant } \\
\text { temperature }\end{array}$ & 1 & 1 & - \\
\hline Cavity walls & $\begin{array}{l}\text { Opaque and } \\
\text { reflective }\end{array}$ & $\begin{array}{c}\text { Constant } \\
\text { temperature }\end{array}$ & 1 & .05 & - \\
\hline Glass sides & $\begin{array}{l}\text { Semi- } \\
\text { transparent }\end{array}$ & Coupled & - & 0 & - \\
\hline $\begin{array}{c}\text { Outer surface of } \\
\text { pipes }\end{array}$ & $\begin{array}{l}\text { Opaque with } \\
\text { selective } \\
\text { coating }\end{array}$ & $\begin{array}{c}\text { Constant } \\
\text { temperature }\end{array}$ & 1 & 0.95 & - \\
\hline
\end{tabular}

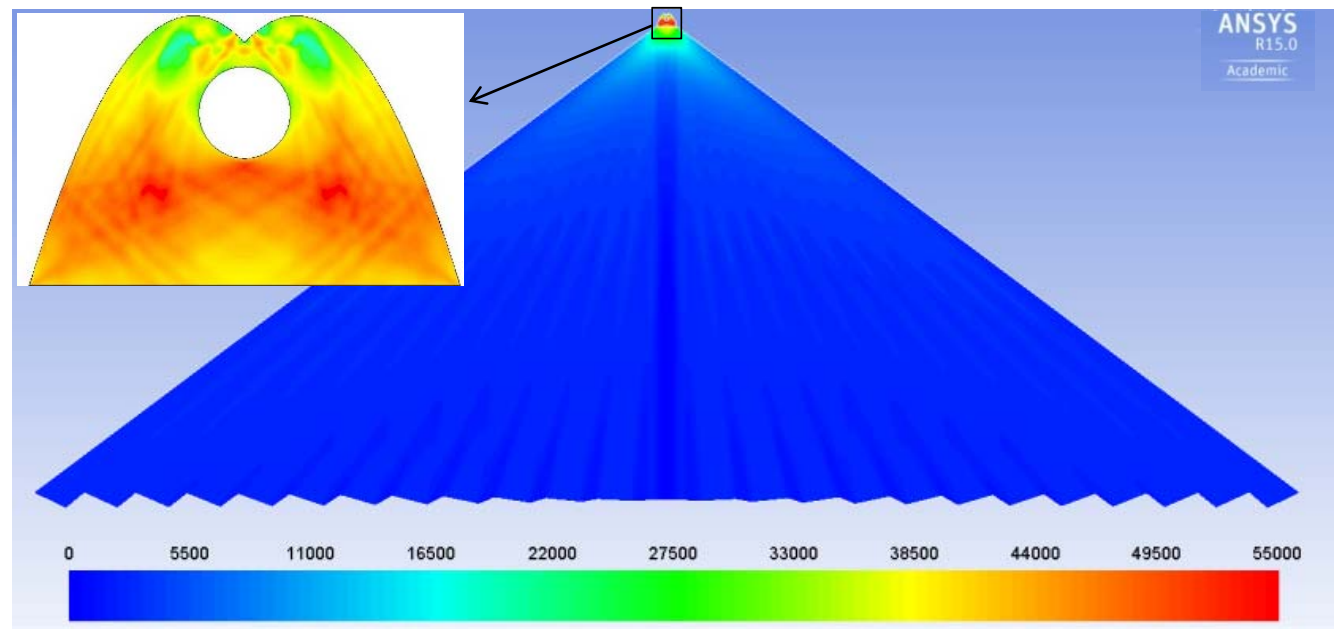

Figure 18: Incident radiation contours $\left[\mathrm{W} / \mathrm{m}^{2}\right]$ for mono-tube receiver above LFR (477k mesh cells and 3×200 angular discretisation) at noon. See Figure 23 for close-up of receiver. 


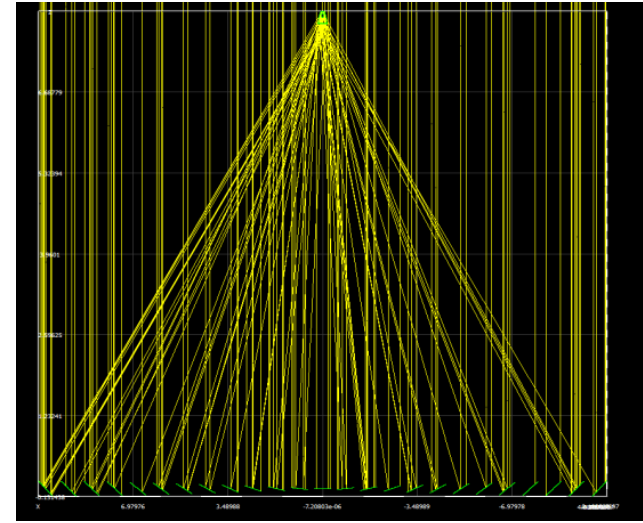

(a)

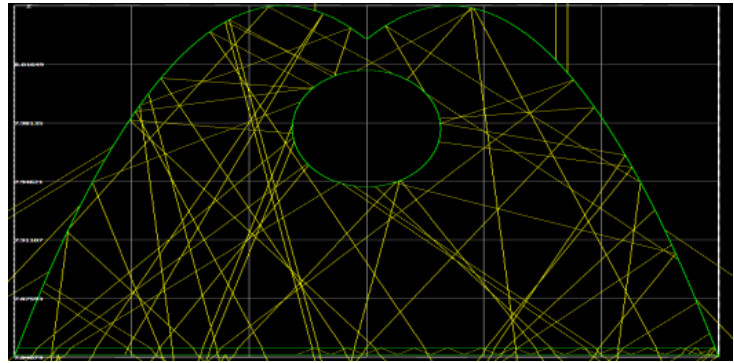

(b)

Figure 19: SolTrace results of converged case (1e6 rays) at noon. (a) Solar field and (b) cavity close-up

Table 5: Comparison of ANSYS FLUENT CFD and SolTrace heat flux - standard LFR with mono-tube receiver

\begin{tabular}{|c|c|c|c|c|}
\hline Method & $\begin{array}{c}\text { Area weighted } \\
\text { average of } \\
\text { absorbed } \\
\text { radiation flux on } \\
\text { pipe [W/m²] }\end{array}$ & $\begin{array}{c}\text { Deviation } \\
\text { percentage of } \\
\text { CFD result from } \\
\text { SolTrace result } \\
\text { (\%) }\end{array}$ & $\begin{array}{c}\text { Total reflected } \\
\text { radiation on } \\
\text { secondary } \\
\text { reflector [W] }\end{array}$ & $\begin{array}{c}\text { Deviation } \\
\text { percentage of } \\
\text { CFD result from } \\
\text { SolTrace result } \\
\text { (\%) }\end{array}$ \\
\hline $\begin{array}{c}\text { CFD (477k mesh, } \\
\text { DO 3×200) }\end{array}$ & 16767 & 0.56 & 6909 & 32.3 \\
\hline $\begin{array}{c}\text { Ray tracing (2e6 } \\
\text { rays) }\end{array}$ & 16674 & 0 & 5221 & 0 \\
\hline
\end{tabular}

\subsection{Test case 5: Compact linear Fresnel receiver with etendue conservation with mono-tube cavity receiver}

The final test case is that of an etendue-conserving compact linear Fresnel reflector (CLFR) field [26, 46, 48], which incorporates multiple slanted receivers and flat mirrors placed along a curve to minimise optical losses in the collector field. The mesh and DO convergence studies yielded a 322000 cell mesh and a 3×400 DO setting, with the same minimum requirement of a million rays in SolTrace for a ray-independent solution.

The corresponding results are displayed in Figures 21 to 23 with the integrated values listed in Table 6. The receiver focal point and its height are the same as above and the total mirror field width of $27.8 \mathrm{~m}$ implies that each receiver receives reflected radiation from about $21 \mathrm{~m}$, the width used for the standard LFR field above. To improve the SolTrace comparison, a solution adaption strategy was followed. This started off with a coarse mesh of $41 \mathrm{k}$ cells, and then adapting after convergence based on gradients of incident radiation. The final result improved on the initial $4 \%$ deviation to provide a value to within $2.5 \%$ of the SolTrace result (sample rays depicted in Figure 22). The detail distributions in Figure 23 show that the better agreement in average value is due to an improved capture of the radiation mainly on the front-facing portion of the tube. Note how the refined mesh also captures the jagged nature of the profile due to each individual flat mirror's focus. The focal point of all the mirrors is at the centre of the tube. 


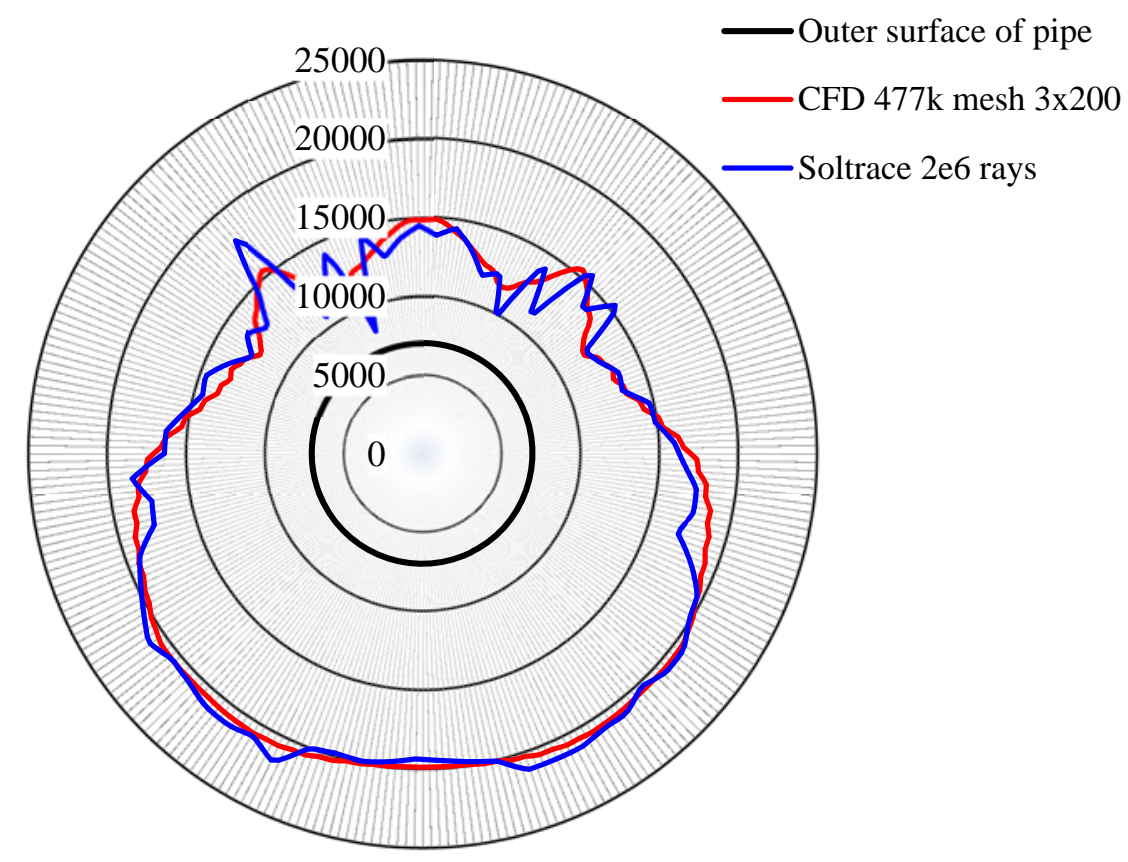

(a)

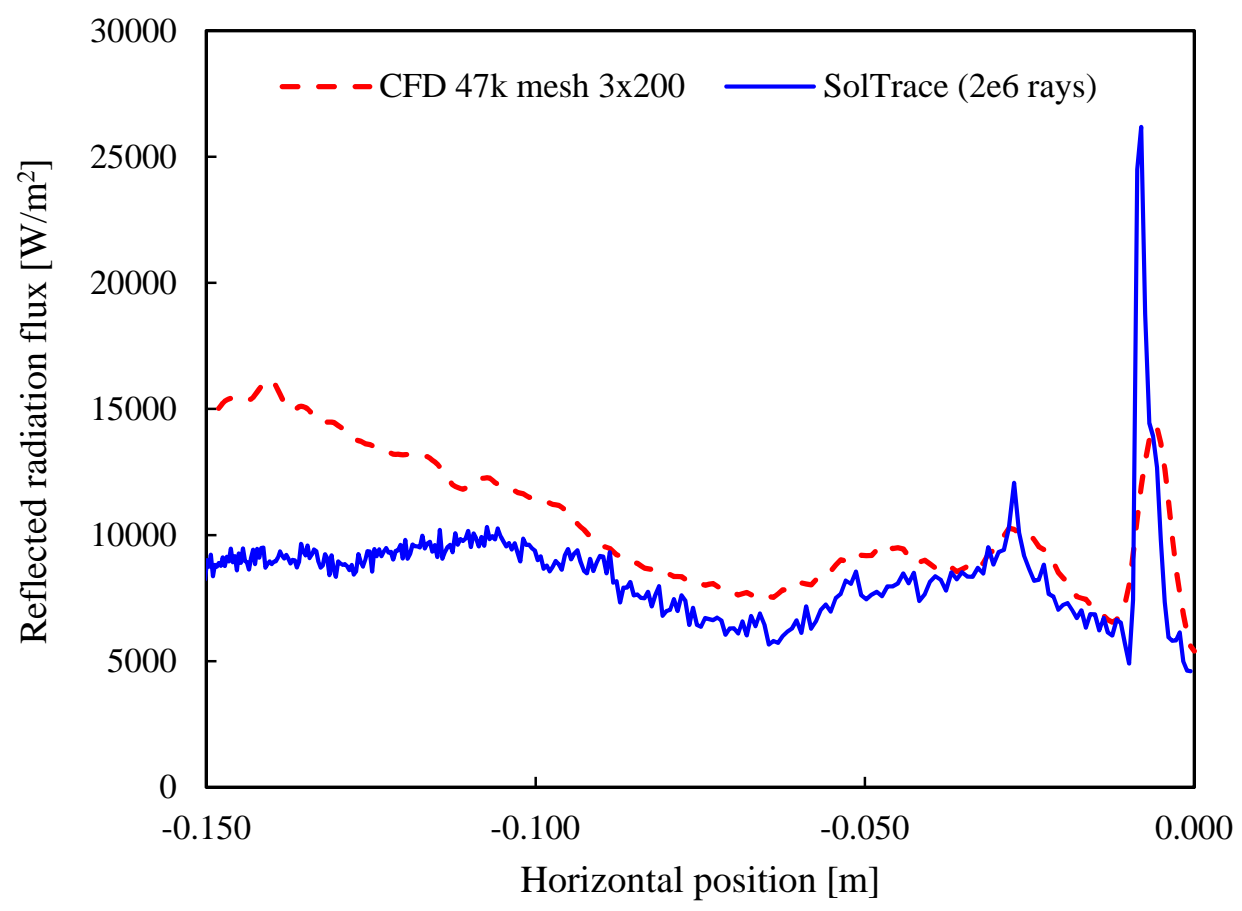

(b)

Figure 20: Comparison of heat flux distribution $\left[\mathrm{W} / \mathrm{m}^{2}\right]$ a) absorbed around absorber tube (Radar plot), b) reflected off secondary reflector (versus horizontal coordinate) obtained by CFD and SolTrace flux - standard LFR with mono-tube receiver 


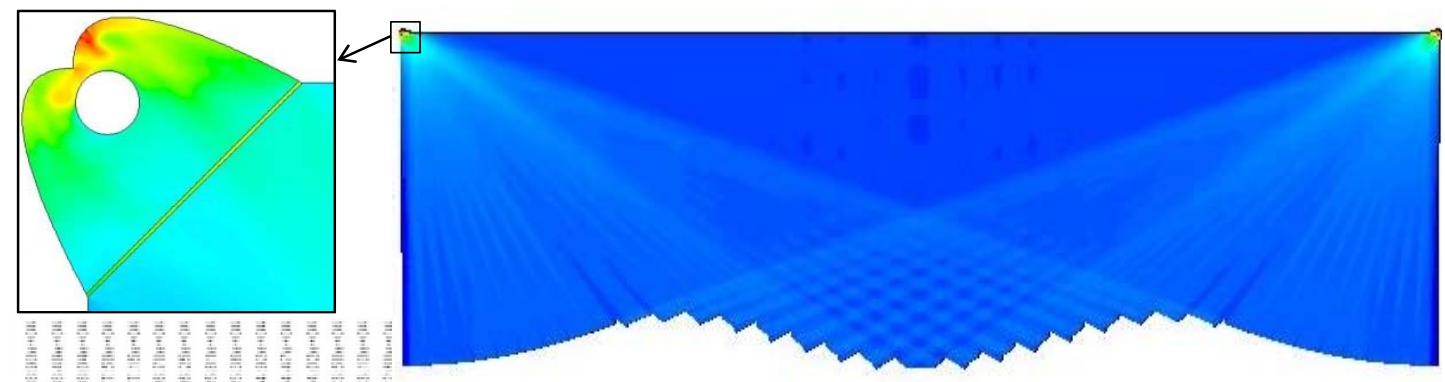

(a)

(b)

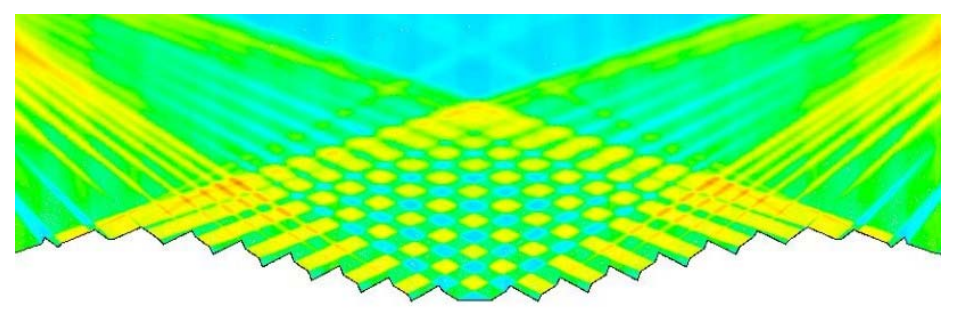

(c)

Figure 21: Incident radiation contours $\left[\mathrm{W} / \mathrm{m}^{2}\right]$ for mono-tube receiver above LFR at noon, (a) close-up for adapted mesh (602k mesh with $3 \times 300 \mathrm{DO}$ ) (b) main field (322k mesh cells and $3 \times 400$ angular discretisation) (c) close-up of mirror region (contours clipped at $5000 \mathrm{~W} / \mathrm{m}^{2}$ )

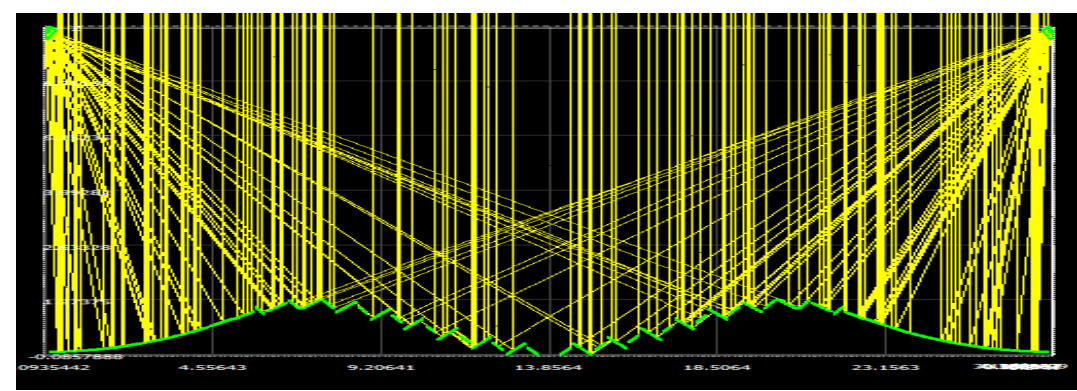

(a)

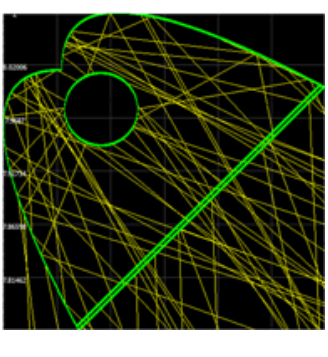

(b)

Figure 22: SolTrace results of converged case (1e6 rays) at noon. (a) Solar field and (b) cavity close-up with sample rays

Table 6: Comparison of ANSYS Fluent CFD and SolTrace heat flux - Etendue-matched CLFR with mono-tube receiver

\begin{tabular}{|l|c|c|}
\hline \multicolumn{1}{|c|}{ Method } & $\begin{array}{c}\text { Area- } \\
\text { weighted } \\
\text { absorbed heat } \\
\text { flux on pipe } \\
{\left[\mathbf{W} / \mathbf{m}^{2}\right]}\end{array}$ & $\begin{array}{c}\text { Deviation percentage } \\
\text { of CFD result from } \\
\text { SolTrace result (\%) }\end{array}$ \\
\hline CFD (322k mesh, DO 3×400) & 17275 & -4.0 \\
\hline CFD (adapted mesh of 602k cells, DO 3×300) & 18457 & +2.5 \\
\hline Ray tracing (1e6 rays) & 18000 & 0 \\
\hline
\end{tabular}




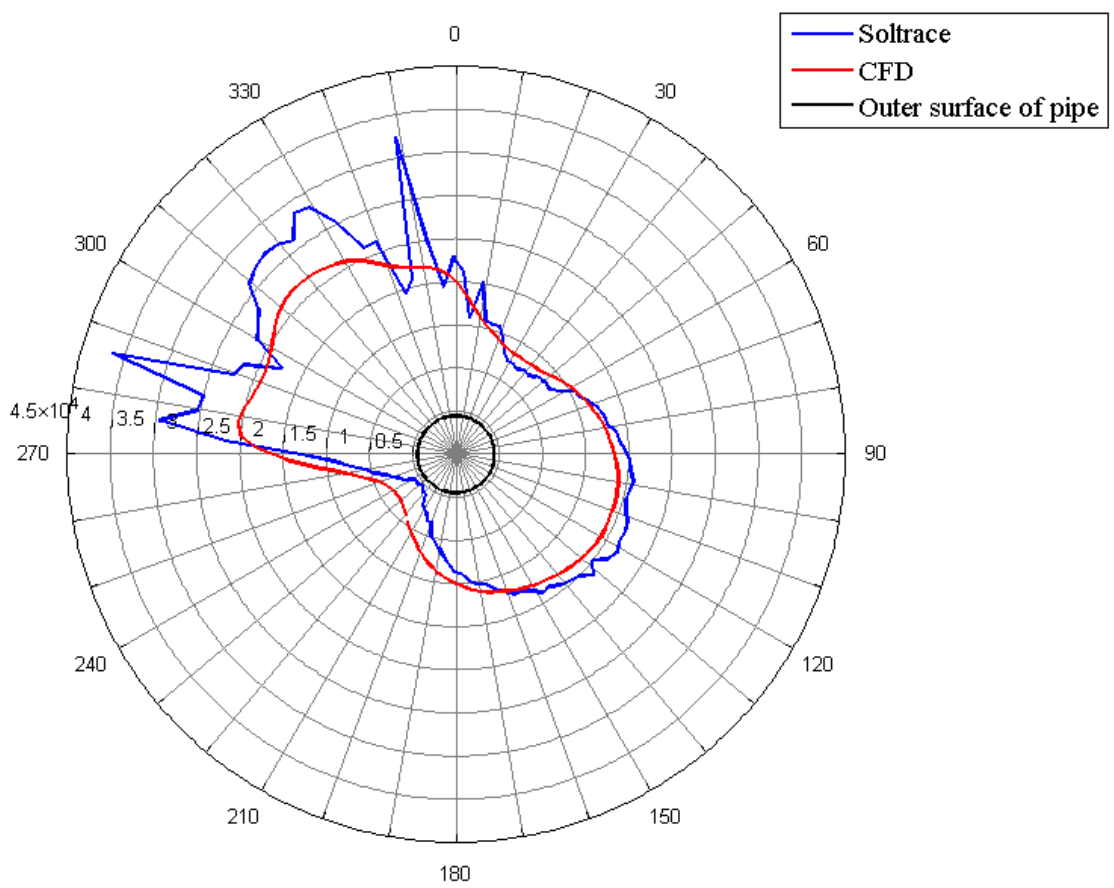

(a)

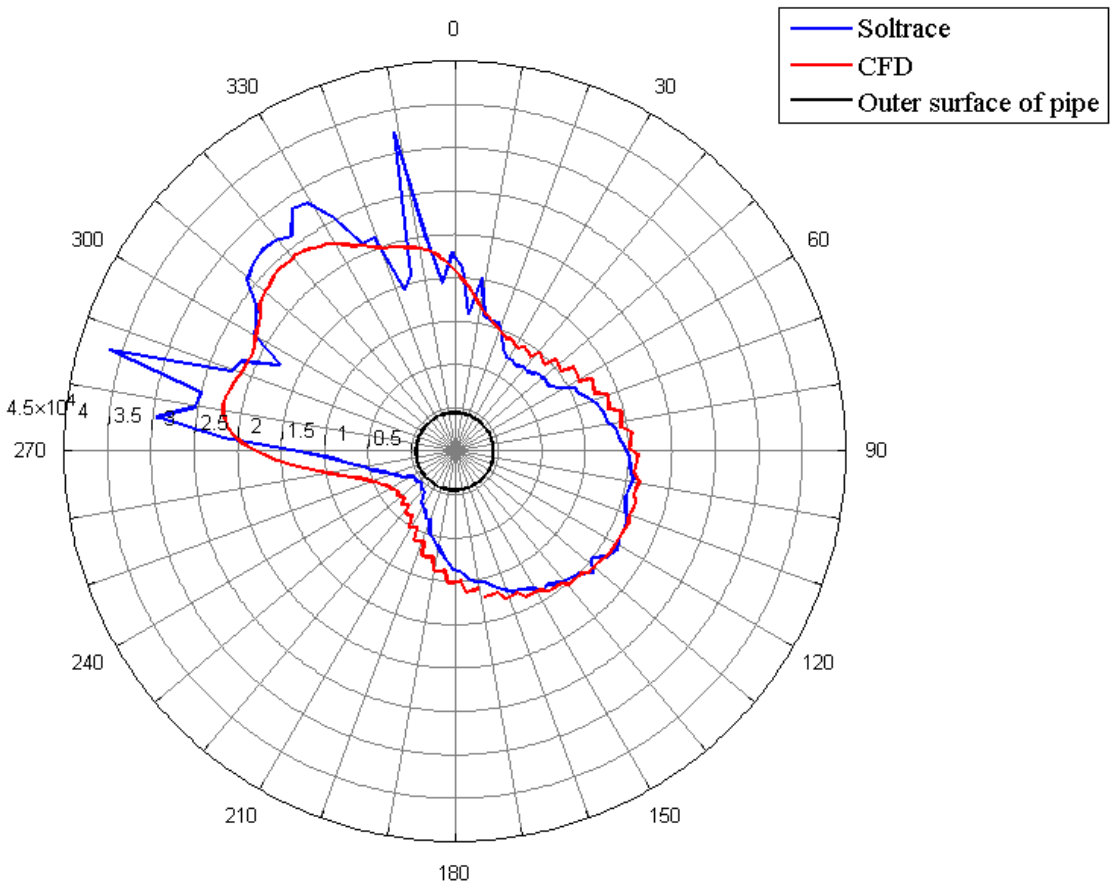

(b)

Figure 23: Radar plot comparison of absorbed heat flux distribution $\left[\mathrm{W} / \mathrm{m}^{2}\right]$ around left receiver absorber tube obtained by CFD and SolTrace (1 million rays) for an incoming DNI of $1000 \mathrm{~W} / \mathrm{m}^{2}$ :

(a) 322k mesh, (DO 3×400), (b) 620k cell adapted mesh, (DO 3×300) 


\section{Discussion}

Based on the results of the test cases, the following advantages and disadvantages of FV CFD ray tracing can be summarised in comparison with MRCT:

\subsection{Advantages}

1. The simulation of the optical performance is integrated into the same software environment as the conjugate heat transfer simulation [21, 49].

2. The understanding that comes from the solution of incident radiation contours aids in the development of improved receiver designs. As an example, Figure 11b explains why the Monte Carlo solution of Figure 10b has the two peaks on the side of the cavity wall. Similar information can be extracted from a Monte Carlo raytracing solution by specifying additional virtual surfaces in the domain and performing ray counts and post-process flux distributions on them, but this requires additional effort that is not necessary with a CFD FV solution.

3. The plotting of iso-surfaces of incident radiation contours provides a visual representation of concentration ratio that could, for instance, aid in the optimal design of an absorber geometry that would have a uniform radiation distribution. This technique could also find application in concentrated photovoltaic (CPV) implementations. As an example of this, consider Figure 24 where contours of isovalues of incident radiation are plotted. The dashed rectangle shown is located in a region of fairly constant and high concentration. An absorbing surface in this region could be expected to have a more even incident radiation distribution than the current tube.

4. Not illustrated in this paper, but as shown by [21] and [49], band-selective coatings and surface radiative properties can easily be incorporated into the DO method using a multiple band or wavelength approach. As shown in these studies, this approach can also incorporate the wavelength-dependent absorption of a glass cover to simulate the greenhouse effect afforded by covering a CSP receiver with a glass window.

5. The treatment of scattering semi-transparent media (e.g. falling particle receivers) can be implemented using CFD.

6. Most MCRT codes provide output data that can be used to couple their optical concentrator modelling with thermal receiver modelling in CFD. The extraction of these data from MCRT codes in a format that is compatible as input to CFD codes may be cumbersome and require additional scripting and processing. When using a single environment, this processing step is eliminated [21]. 

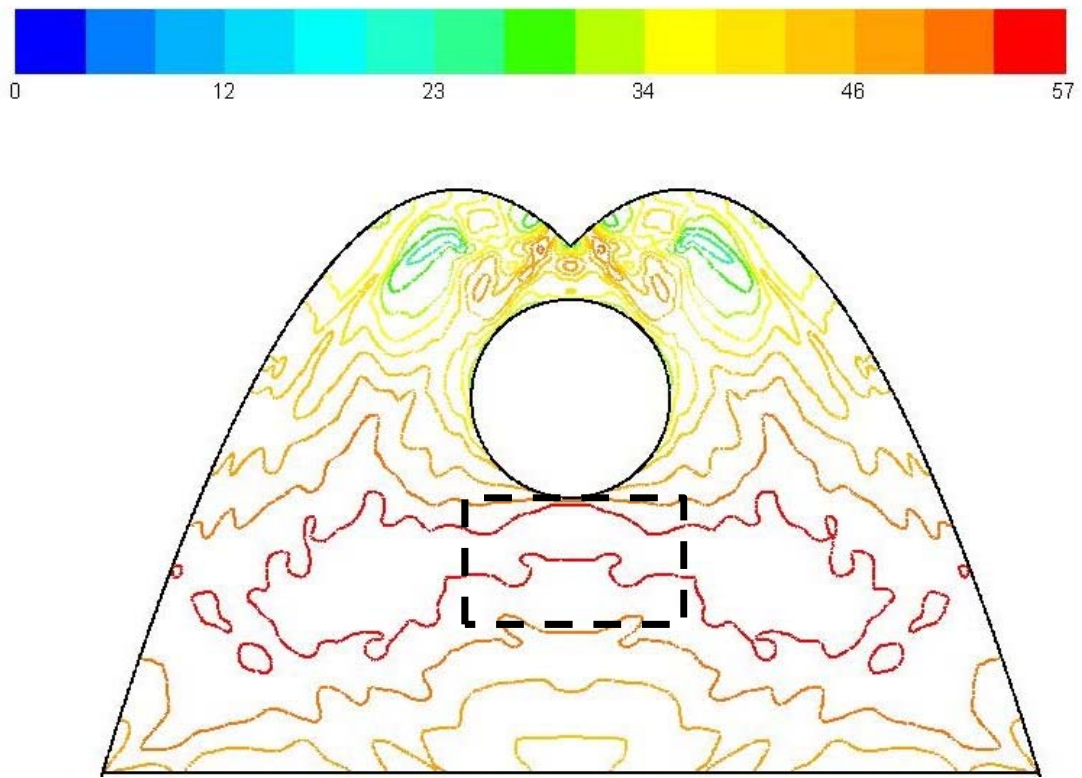

Figure 24 - Iso-values of incident radiation in receiver [suns] - LFR test case. 1 sun $=1000 \mathrm{~W} / \mathrm{m}^{2}$.

7. The single software environment, at least as incorporated into ANSYS WorkBench, allows easy parameterisation and optimization of a proposed CSP geometry [29].

\subsection{Disadvantages}

1. The main disadvantage of the CFD approach is its cost compared with the MCRT method. Ref. 21 performed an extensive study of the influence of spatial mesh and control angle count on the computing time and how these settings affect accuracy. E.g., a $3 \times 100$ angular discretisation for an 86,725 mesh count gave a 5\% underprediction of the total flux in an LFR test case similar to Test case 4 in this paper. It required 3958s to solve on 5 cores of an i7 machine, increasing to 7700s when increasing the counts to achieve $1 \%$ accuracy. In comparison, a 2-million ray SolTrace run of Test case 4 required about 12 seconds on the same machine. Apart from the run-time requirement, the CFD approach also includes a considerable memory budget when compared with MCRT. Associated with this cost is the cost of conducting a mesh refinement and DO discretisation refinement study to determine the combination of these two factors in limiting the ray-effect and false scattering errors for a specified accuracy. Computational power is however becoming less expensive as the processor technology is constantly improving.

2. Because of its high cost, it is recommended with current computational resources that CFD ray tracing only be used for line concentration, i.e. 2-D applications of CSP. Point concentration can be considered if the geometry is axi-symmetric, i.e. is modelled using a 2-D mesh. But even here, the DO settings have to be refined in both the $\theta$ and $\phi$ directions, with the result that while it is not as expensive as full 3 -D ray tracing, it can still lead to a high computational cost overhead. 


\section{Conclusions and recommendations}

The paper described the use of CFD as a ray-tracing tool using a finite volume implementation of the discrete ordinates solution of the radiative transfer energy equation in the commercial code ANSYS Fluent. The following conclusions can be drawn from the work:

- In the five test cases supplied, which ranged from a simple cavity to a tubular cavity to one parabolic trough and two linear Fresnel reflector applications incorporating a mirror field and a cavity receiver with a secondary reflector, the CFD result compared very well with Monte Carlo results, either obtained from literature or determined using SolTrace.

- Within the realm of thermoflow simulations, the accuracy of the CFD solution is determined exclusively by whether the mesh is fine enough, whereas for radiation modelling, both the mesh and DO settings' refinement affects the solution. The model requirements should be determined through mesh and DO independence studies.

- Modelling radiation accurately in a CFD environment can be achieved by reducing the numerical errors associated with finite volume solvers. The errors associated with ray effects can be reduced by increasing the control angle count of the model in the phi direction $\left(N_{\phi}\right)$, while the errors associated with false scattering can be reduced by increasing the spatial mesh count and using a higher-order DO model. It should be noted that these error reduction strategies should be used in conjunction for the most accurate results.

- The mesh and DO requirements depend on the optical complexity of the model. If radiation beam propagation occurs in a large number of different directions, the optical modelling within CFD needs to scale accordingly to approximate the discrete intervals accurately for what is a continuous physical phenomenon.

- The CFD approach has some advantages over the standard ray-tracing approach as highlighted in the paper, especially when considering complex optical properties of opaque surfaces, e.g., spectral and temperature variation in emissivity.

\section{Acknowledgements}

The authors would like to acknowledge the support of the University of Pretoria (South Africa) and the South African National Research Foundation (DST-NRF Solar Spoke).

\section{References}

[1] Gadi, M. B., 2000. Design and simulation of a new energy- conscious system (CFD and solar simulation), Applied Energy, 65, 251-256.

[2] Yadav, A.S., Bhagoria, J.L. 2013. Heat transfer and fluid flow analysis of solar air heater: A review of CFD approach. Renewable and Sustainable Energy Reviews.23, 60-79.

[3] Allouche, Y, Bouden, C., Varga S., 2014. A CFD analysis of the flow structure inside a steam ejector to identify the suitable experimental operating conditions for a solardriven refrigeration system, International Journal of Refrigeration, 39, 186-195. 
[4] Muñoz, J., Abánades, A., 2011. Analysis of internal helically finned tubes for parabolic trough design by CFD tools, Applied Energy, 88, 4139-4149.

[5] Fornarelli, F., Camporeale, S.M., Fortunato, B., Torresi, M, Oresta, P., Magliocchetti, L., Miliozzi, A., Santo, G., 2016. CFD analysis of melting process in a shell-and-tube latent heat storage for concentrated solar power plants, Applied Energy, 164, 711-722.

[6] Pointner, H., de Gracia, A., Vogel, J., Tay, N.H.S., Liu, M., Johnson, M., Cabeza, L.F., 2016. Computational efficiency in numerical modeling of high temperature latent heat storage: Comparison of selected software tools based on experimental data, Applied Energy, 161, 337-348.

[7] Xu, B., Li, P., Chan, C., 2015. Application of phase change materials for thermal energy storage in concentrated solar thermal power plants: A review to recent developments, Applied Energy, 160, 286-307.

[8] Fasel, H.F., Meng, F., Shams, E., Gross A., 2013. CFD analysis for solar chimney power plants, Solar Energy, 98, 12-22.

[9] Facão, J., Oliveira A.C., 2011, Numerical simulation of a trapezoidal cavity receiver for a linear Fresnel solar collector concentrator, Renewable Energy, 36, 90-96.

[10] Lobón, D.H., Baglietto, E., Valenzuela, L., Zarz, E., 2014. Modeling direct steam generation in solar collectors with multiphase CFD, Applied Energy, 113, 1338-1348.

[11] Garbrecht, O., Al-Sibai, F., Kneer, R., Wieghardt, K., 2013. CFD-simulation of a new receiver design for a molten salt solar power tower, Solar Energy. 90, 94-106.

[12] Hachicha, A.A., Rodríguez, I., Castro, J., Oliva, A., 2013. Numerical simulation of wind flow around a parabolic trough solar collector, Applied Energy, 107, 426-437.

[13] Martinek, J., Weimer, A.W., 2012. Evaluation of finite volume solutions for radiative heat transfer in a closed cavity solar receiver for high temperature solar thermal processes. Int. J. Heat Mass Tr., 58(1), 585-596.

[14] Hachicha, A.A., 2013. Numerical modelling of a parabolic trough solar collector, $\mathrm{PhD}$ thesis, Polytechnic University of Catalunya, Terrassa.

[15] He, Y.L., Xiao, J., Cheng, Z.D., Tao, Y.B., 2011. A MCRT and FVM coupled simulation method for energy conversion process in parabolic trough solar collector. Renew. Energy 36, 976-985.

[16] Qiu, Y., He, Y.L., Cheng, Z.D., Wang, K., 2015. Study on optical and thermal performance of a linear Fresnel solar reflector using molten salt as HTF with MCRT and FVM methods. Appl. Energy 146, 162-173.

[17] Wang, W.J., Laumert, B., Xu, H.X., Strand, T., 2015. Conjugate heat transfer analysis of an impinging receiver design for a dish-Brayton system. Solar Energy 119, 298-309.

[18] Miller, W.F., Reed, W.H., 1977. Ray-effect mitigation methods for two-dimensional neutron transport theory. Nuclear Science and Engineering, 62, 391-411.

[19] Brunner, T.A., 2002. Forms of approximate radiation transport, SANDIA Report, SAND2002-1778.

[20] Chai, J.C., Patankar, S.V., 2006. Discrete-ordinates and finite-volume methods for radiative heat transfer. In Handbook of Numerical Heat Transfer, 2nd edition, John Wiley \& Sons.

[21] Moghimi, M.A., Craig, K.J., Meyer, J.P., 2015a. A novel computational approach to combine the optical and thermal modelling of linear Fresnel collectors using the finite volume method, Solar Energy, 116, 407-427.

[22] Li, H., 2004. Reduction of false scattering in arbitrarily specified discrete directions of the discrete ordinates method, J. Quant. Spectrosc. Radiat. Transfer, 86, 215-222. 
[23] Lichty, P., Perkins, C., Woodruff, B., Bingham, C., Weimer, A., 2010. Rapid high temperature solar thermal biomass gasification in a prototype cavity reactor. Journal of Solar Energy Engineering, 132(1), 011012-011012.

[24] Dudley, V., Kolb, G., Sloan, M., Kearney, D., 1994. SEGS LS-2 solar collector - test results. Technical report, Report of Sandia National Laboratories (SAND94-1884).

[25] Bernhard, R., Laabs, H.-G., De Lalaing, J., Eck, M., Eickhoff, M., Pottler, K., Morin, G., Heimsath, A., Georg, A., Häberle, A., 2008. Linear Fresnel Collector demonstration on the PSA Part 1 - Design, construction and quality control. In: 14th International Symposium on Concentrated Solar Power and Chemical Energy Technologies, SolarPACES 2008, Las Vegas, USA.

[26] Chaves, J., Collares-Pereira, M., 2010. Etendue-matched two-stage concentrator with multiple receivers. Solar Energy, 84, 196-207.

[27] Wendelin, T., Dobos, A., Lewandowski, A., 2013. SolTrace: A ray-tracing code for complex solar optical systems, NREL - Technical Report, 303, 275-300.

[28] Modest, M.F., 2013. Radiative Heat Transfer, 3rd edition, Elsevier.

[29] Moghimi, M.A., Craig, K.J., Meyer, J.P., 2015b. Optimization of a trapezoidal cavity absorber for the Linear Fresnel Reflector Solar Energy, 119, 343-361.

[30] Dhall, A., Datta, A.K., Torrance, K.E., Almeida, M.F., 2009. Radiative heat exchange modeling inside an oven, AIChE Journal: Bioengineering, Food, and Natural Products, 55, 2448-2460.

[31] Cengel, Y.A., Ghajar, A.J., 2010. Heat and Mass Transfer Fundamentals and Applications, 4th edition, McGraw-Hill.

[32] Bennett, H.E., Porteus, J.O., 1961. Relation between surface roughness and specular reflectance at normal incidence, U.S. Naval Ordnance Test Station.

[33] Mellott, N.P., Brantley, S.L., Hamilton, J.P., Pantano, C.G., 2001. Evaluation of surface preparation methods for glass, Surf. Interface Anal., 31, 362-368.

[34] ANSYS, 2013. Fluent Theory manual, version 15, ANSYS Incorporated.

[35] Coelho, P.J., 2002. The role of ray effects and false scattering on the accuracy of the standard and modified discrete ordinates methods, J. Quant. Spectrosc. Radiat. Transfer, 73, 231-238.

[36] Kim, T., Lee, H.S., 1989. Radiative transfer in two-dimensional anisotropic scattering media with collimated incidence, J. Quant. Spectrosc. Radiat. Transfer, 42, 225-238.

[37] Jessee, J.P., Fiveland, W.A., 1997. Bounded, high resolution differencing schemes applied to the discrete ordinates method, J. Thermophysical Heat Transfer, 11, 540548.

[38] Chai, J.C., Lee, H.S., Patankar, S.V., 1993. Ray effect and false scattering in the discrete ordinates method. Numer Heat Transfer, Part B, 24, 373-389.

[39] Mutuberria, A., Monreal, A., Albert, A., Blanco, M., 2011. Results of the empirical validation of Tonatiuh at Mini-Pegase CNRS-PROMES facility, in SolarPACES, Seville, 2011.

[40] Meller, Y., Tracer - a free ray-tracing library for Python/Scipy, https://github.com/yosefm/tracer. 9 Aug 2015.

[41] Roccia, J.P., Piaud, B., Coustet, C., Caliot, C., Guilliot, E., Flamant, F., Deltorre, J., 2012. SOLFAST, a ray-tracing Monte Carlo software for solar concentrating facilities, Journal of Physics conference series, 369, 012029.

[42] Bode, S.J., Gauché, P., 2012. Review of optical software for use in concentrated solar power systems, Proceedings of SASEC 2012. Stellenbosch, South Africa. 
[43] Garcia, P., Ferriere, A., Bezian, J.-J., 2008. Codes for solar flux calculations dedicated to central receiver system applications: A comparative review, Solar Energy, 82, 189197.

[44] Shuai, Xia, X.L., Tan, H.P., 2008. Radiation performance of dish solar concentrator/cavity receiver systems, Solar Energy, 82, 13-21.

[45] Cheng, Z.D., He, Y.L., Xiao, J., Tao, Y.B., Xu, R.J., 2010. Three-dimensional numerical study of heat transfer characteristics in the receiver tube of parabolic trough solar collector. International Communications in Heat and Mass Transfer, 37, 782-787.

[46] Moghimi, M.A., Rungasamy, A. Craig, K.J., Meyer, J.P., 2016. Introducing CFD in the optical simulation of linear Fresnel collectors, in: SolarPACES 2015, Cape Town, South Africa, AIP Conference Proceedings 1734, 020015.

[47] Selig, M., Mertins, M., 2010. From saturated to superheated direct solar steam generation - technical challenges and economical benefits, in: SolarPACES 2010, Perpignan, France.

[48] Rungasamy, A.E., Craig, K.J., Meyer, J.P., 2015. 3-D CFD modeling of a slanted receiver in a compact linear Fresnel plant with etendue-matched mirror field, in: SolarPACES 2014, Beijing, China, Energy Procedia, 69, 188-197.

[49] Craig, K.J., Gauché, P., Kretzschmar, H., 2014. CFD analysis of solar tower hybrid pressurized air receiver (HPAR) using a dual-banded radiation model, Solar Energy, 110, 338-355. 